This item was submitted to Loughborough's Research Repository by the author.

Items in Figshare are protected by copyright, with all rights reserved, unless otherwise indicated.

\title{
Development of a multi-body computational model of human head and neck
}

PLEASE CITE THE PUBLISHED VERSION

PUBLISHER

(C) Professional Engineering Publishing

VERSION

VoR (Version of Record)

LICENCE

CC BY-NC-ND 4.0

REPOSITORY RECORD

van Lopik, David W., and Memis Acar. 2019. "Development of a Multi-body Computational Model of Human Head and Neck". figshare. https://hdl.handle.net/2134/4533. 
This item was submitted to Loughborough's Institutional Repository (https://dspace.lboro.ac.uk/) by the author and is made available under the following Creative Commons Licence conditions.

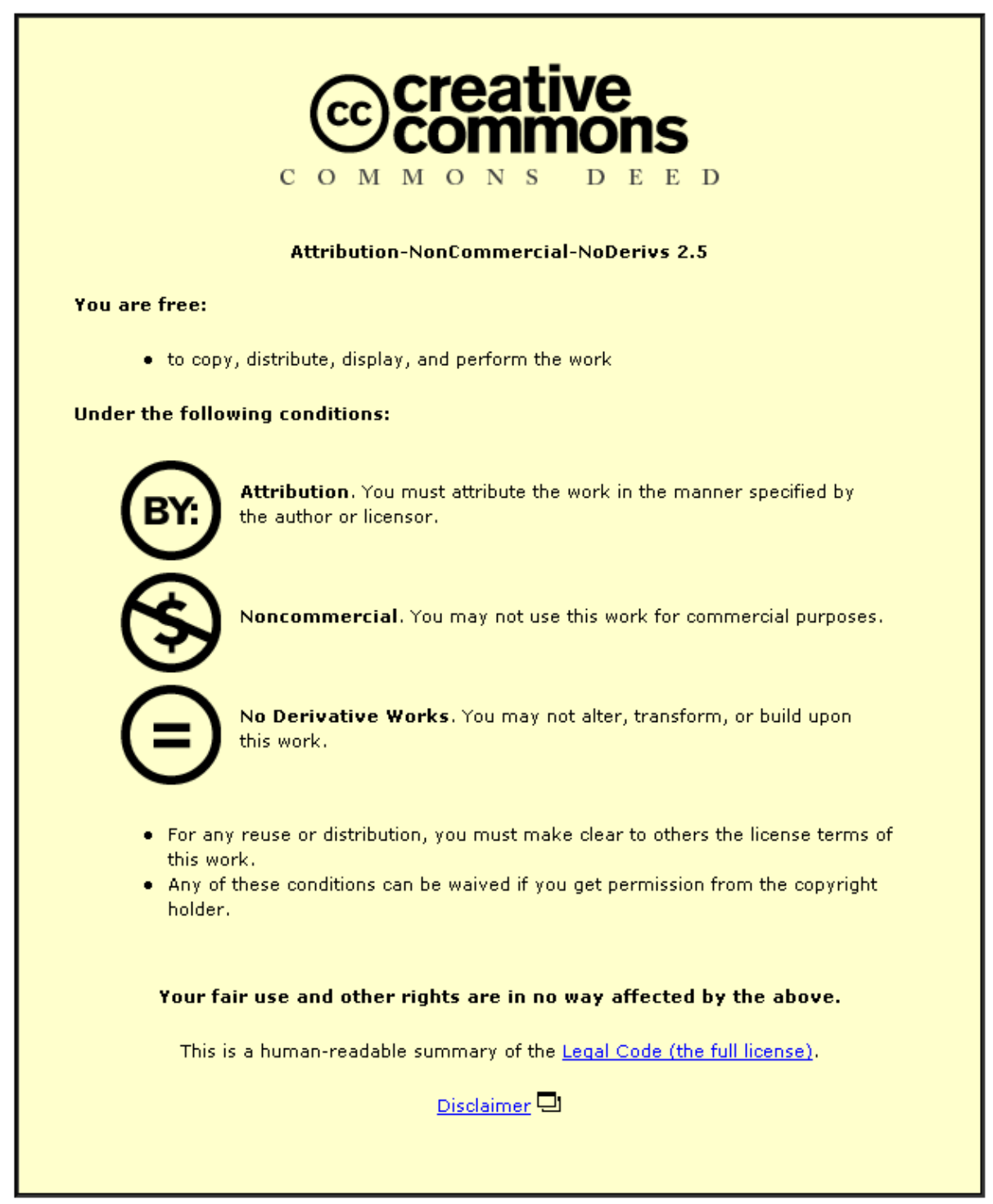

For the full text of this licence, please go to: http://creativecommons.org/licenses/by-nc-nd/2.5/ 


\title{
Development of a multi-body computational model of human head and neck
}

D W van Lopik and M Acar*

School of Mechanical and Manufacturing Engineering, Loughborough University, Loughborough, UK

The manuscript was received on 28 June 2006 and was accepted after revision for publication on 18 January 2007.

DOI: 10.1243/14644193JMBD84

\begin{abstract}
Experimental studies using human volunteers are limited to low acceleration impacts while whole cadavers, isolated cervical spine specimens, and impact dummies do not normally reflect the true human response. Computational modelling offers a cost effective and useful alternative to experimental methods to study the behaviour of the human head and neck and their response to impacts to gain insight into injury mechanisms.

This article reports the approach used in the development of a detailed multi-body computational model that reproduces the head and cervical spine of an adult in the upright posture representing the natural lordosis of the neck with mid-sagittal symmetry. The model comprises simplified but accurate representations of the nine rigid bodies representing the head, seven cervical vertebrae of the neck, and the first thoracic vertebra, as well as the soft tissues, i.e. muscles, ligaments, and intervertebral discs. The rigid bodies are interconnected by non-linear viscoelastic intervertebral discs elements in flexion and extension, non-linear viscoelastic ligaments and supported through frictionless facet joints. Eighteen muscle groups and 69 individual muscle segments of the head and neck on each side of the body are also included in the model. Curving the muscle around the vertebrae and soft tissues of the neck during the motion of the neck is also modelled. Simulation is handled by the multi-body dynamic software MSC.visuaNastran4D. Muscle mechanics is handled by an external application, Virtual Muscle, in conjunction with MSC.visuaNastran4D that provides realistic muscle properties. Intervertebral discs are modelled as non-linear viscoelastic material in flexion and extension but represented by 'bushing elements' in Visual Nastran 4D, which allows stiffness and damping properties to be assigned to a joint with required number of degrees of freedom of the motion. Ligaments are modelled as non-linear viscoelastic spring-damper elements.

As the model is constructed, the cervical spine motion segments are validated by comparing the segment response to published experimental data on the load-displacement behaviour for both small and large static loads. The response of the entire ligamentous cervical spine model to quasi-static flexion and extension loading is also compared to experimental data to validate the model before the effect of muscle stiffening is included. Moreover the moment-generating capacity of the neck muscle elements has been compared against in vivo experimental data.

The main and coupled motions of the model segments are shown to be accurate and realistic, and the whole model is in good agreement with experimental findings from actual human cervical spine specimens. It has been shown that the model can predict the loads and deformations of the individual soft-tissue elements making the model suitable for injury analysis. The validation of the muscle elements shows the morphometric values, origins, and insertions selected to be reasonable. The muscles can be activated as required, providing a more realistic representation of the human head and neck. The curved musculature results in a more realistic representation of the change in muscle length during the head and neck motion.
\end{abstract}

\footnotetext{
*Corresponding author: School of Mechanical and Manufacturing Engineering, Loughborough University, Loughborough, Leicestershire LE11 3TU, UK.email:m.acar@lboro.ac.uk
} 
Keywords: cervical spine, head and neck model, multi-body computational model, vertebrae, ligaments, muscle models, Virtual Muscle

\section{INTRODUCTION}

Whiplash injury to the human neck is a frequent consequence of automobile accidents and has been a significant public health problem for many years. Soft-tissue injuries to the cervical spine are basically defined as an injury in which bone fracture does not occur or is not readily apparent. A whiplash injury is therefore an injury to one or more of the many ligaments, intervertebral discs, facet joints or muscles of the neck. Although many different theories have been proposed no definitive answer on the cause of whiplash injuries has yet been established.

To gain insight into injury mechanisms of the cervical spine during motor vehicle collisions, experimental studies are conducted using human volunteers, whole cadavers, isolated cervical spine specimens, and impact dummies. Testing on human volunteers is limited to situations that are not traumatic and hence only low acceleration impacts can be studied. Cadaver and dummy testing, where realistic impact conditions can be simulated, does not reflect the true human response due to absence of live anatomical structure. On the other hand computational models, although may have limitations in perfectly simulating the motion of human head and neck, offer a cost effective and useful alternative to experimental methods providing information on simulated situations that could not otherwise be obtained. Computational models can be used as an effective and convenient tool to study injury mechanisms and causes of injury by comparing the loads applied to soft tissue as a result of impact scenarios with the critical values of load-bearing capacity of soft tissue.

Multi-body models that can include many anatomical details are computationally efficient with respect to finite element models but there is a need for more detailed and accurate multi-body dynamic model. Several multi-body models of the human head and neck were developed in recent years. Jakobsson et al. [1] presented a multi-body head and neck model that formed a part of the complete spine designed to work in the sagittal plane. The head-neck system was driven by revolute joints which applied resistance to motion according to the specified torque versus rotation functions. The time-dependency of the muscle reflexes was not considered in this model.

De Jager [2] model was the first detailed head and neck model, comprising linear viscoelastic intervertebral discs, non-linear viscoelastic ligaments, active muscles, and frictionless facet joints. Muscles were modelled as straight line elements. This model was validated only against frontal and lateral acceleration impacts and showed reasonable responses. Van den Kroonenberg et al. [3] used the De Jager's model in their multi-body rear impact human model. Yamazaki et al. [4] optimized De Jager's model by changing the joint resistance properties by using data from one volunteer only from the tests performed by JARI with a standard seat and at an impact speed of $8 \mathrm{~km} / \mathrm{h}$. The selected test was then simulated with muscle activation levels set to zero.

Van Der Horst's [5] is similar to De Jagers' model, but differs from it in that segmented contractile muscles follow the curvature of the neck, providing more realistic muscle force lines of action. The model was first validated for frontal and lateral impacts. Then, rear-end sled experiments involving volunteers (on a standard car seat with head restraint and on a rigid seat without head restraint) and cadavers (on a rigid seat without head restraint) were simulated to validate the model dynamically. Substantial differences were observed between simulations done with active and passive muscle behaviour. Active muscle activation was shown to be necessary in obtaining better agreement with the volunteer responses regarding the rigid seat experiments without head restraint. However, in the rear-end impact simulations with a standard seat with head restraint, both the passive and active model showed reasonable poor correlation with the volunteer data.

Stemper et al. [6] built a model of head and neck in Madymo. The model consist of a rigid head, rigid vertebrae, non-linear viscoelastic intervertebral discs, frictionless facet joints, non-linear viscoelastic ligaments, and segmented contractile muscles. Nonlinear elastic contact interaction was defined between adjacent vertebrae. Although both active and passive muscle properties were defined, active muscle effects were not considered. The model was validated by using global, segmental, and facet joint kinematic corridors developed from a series of cadaver head-neck complexes with intact skin and musculature.

The model of Van Der Horst [5] stands out to be the one having a more complete validation with regard to the others. However, the responses of this model were not satisfactory at all times. Soft-tissue injures of the cervical spine can be studied by detailed computational models validated by volunteer tests and experimental data, by simulating different loading conditions and investigating the effect of such forces and moments on soft tissue loading. Such forces and moments can then be compared with experimentally determined limits of loads that soft-tissue 
elements can tolerate. This requires a detailed and more accurate model validated for all possible conditions. Present model offers a more accurate bony structure, a more detailed muscle mapping, and more complex muscle model that allows flexible muscle activation timing and activation levels than the previously reported models.

\section{METHOD}

The three-dimensional multi-body computational model developed represent the head and neck of an adult with mid-sagittal symmetry in the upright posture having natural lordosis, that is, capable of simulating the dynamic behaviour in response to automobile impacts. First the multi-body model of the cervical spine has been developed. Then the individual motion segment response of the cervical spine has been validated using quasi-static loading and experimental data from literature. Then the complete model has been validated for dynamic applications, i.e. for frontal, lateral, and rear impact simulations, which will be the subject of another article. It is intended that the model is able to predict the resulting motion of the head with respect to the torso, the local kinematics of the individual vertebrae, and the loads and deformations of the surrounding soft tissues providing a better understanding of the possible causes of injury.

Boney elements are modelled using published anatomical data and using a Solid Edge CAD system. Vertebrae are represented as simplified models but maintaining all essential details for kinematics and soft tissue attachment. Then the model is imported into MSC.visuaNastran4D, a multi-body dynamic modelling environment. Muscles are modelled using an external modelling tool called Virtual Muscle, which is capable of variable activation levels and timing. A complex muscle structure was represented by 18 muscle groups and 69 muscle elements on each side of the body. Published anatomical data were used for muscle properties and attachment points. Intervertebral discs are modelled as non-linear viscoelastic material in flexion and extension but represented by 'bushing elements' in Visual Nastran 4D, which allows stiffness and damping properties to be assigned to a joint with required number of degrees of freedom of the motion. Ligaments are modelled as non-linear viscoelastic spring-damper elements.

\section{MODELLING RIGID HEAD AND VERTEBRAE}

The model comprises nine rigid bodies that represent the head $(\mathrm{C} 0)$, the seven cervical vertebrae $(\mathrm{C} 1-\mathrm{C} 7)$ of the neck, and the first thoracic vertebrae (T1). The vertebrae are simplified but accurate representations of actual human vertebrae. T1 serves as the base of the head-neck model and is located at the origin of the global coordinate system. The local coordinate system of T1 is aligned with the global coordinate system with the $x$-axis pointing forward, the $y$-axis to the left, and the $z$-axis pointing upward. Figure 1 shows the basic configuration of the rigid bodies of the model from the occiput to $\mathrm{T} 1$.

\subsection{Configuration of the lower cervical spine}

The initial configuration of the vertebrae (C2-T1) was based on a number of studies quantifying the three-dimensional anatomy of the cervical spine. The mid-sagittal configuration of $\mathrm{C} 2-\mathrm{C} 7$ was derived from Nissan and Gilad [7] following a similar approach as developed by De Jager [2]. The vertebral body and transverse process widths, pedicle angles, and spinal canal dimensions were based on Panjabi et al. [8] and the position and orientation of the articular facets for C2-T1 were derived from Panjabi et al. [9].
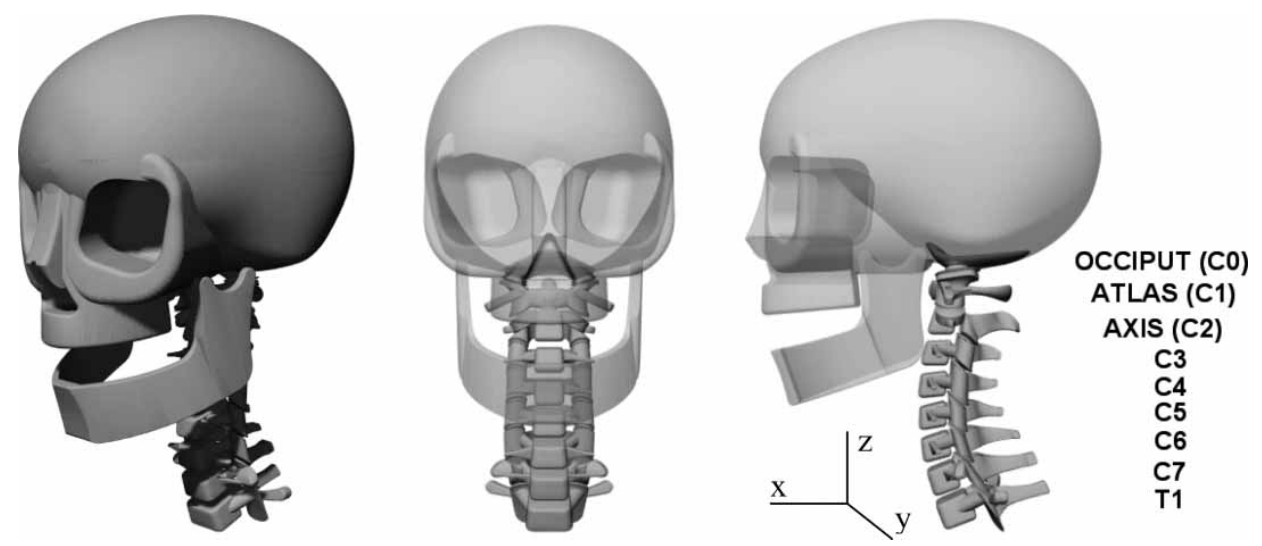

Fig. 1 Isometric, frontal, and left lateral view showing the configuration of the rigid bodies of the multi-body model 


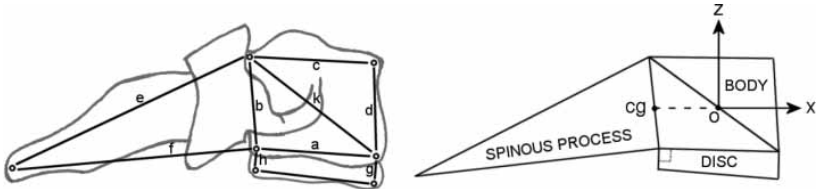

Fig. 2 Left: Sagittal plane approximation of vertebra as presented by Nissan and Gilad. Right: Simple geometric representation of vertebra showing centre of gravity (cg) and origin (o) position

Nissan and Gilad used lateral radiograms of more than 130 erect standing volunteers to determine midsagittal dimensions of cervical and lumbar vertebrae and intervertebral discs. The vertebral body is approximated by a quadrangle with corners at the four extremes of the body's outline; a fifth point represents the most dorsal aspect of the spinous process (Fig. 2). The heights of the intervertebral discs were measured between the superior corners of the lower vertebrae and the inferior corners of the superior adjacent vertebrae.

The following assumptions as described by De Jager [2] were employed in the construction of the model.

1. The posterior height $h$ of the intervertebral disc was measured perpendicular to the inferior edge $a$ of the upper vertebral body.

2. The geometric centre of each vertebra lies at the centre of the diagonal $k$ connecting opposite corners of the vertebral body.

3. The origin of the local coordinate system of each vertebra was positioned at the geometric centre of the body thus having the $x$-axis parallel to the lower end plate $a$.

4. The centre of gravity of each vertebra lies on the posterior side $b$ of the body in line with the body's geometric centre along the $x$-axis.

The above assumptions allow for the positions and orientations of vertebrae $\mathrm{C} 2-\mathrm{C} 7$ to be determined for the initial position of the model. The mid-sagittal dimensions of $\mathrm{T} 1$ were derived from the $\mathrm{C} 7-\mathrm{T} 1$ disc dimensions reported by Nissan and Gilad and from quantitative three-dimensional data presented by Panjabi et al. [10]. The origin and local coordinate system of $\mathrm{T} 1$ is positioned at $(0,0,0)$ of the global coordinate system for the model. The position and orientation of each of the vertebrae are described relative to $\mathrm{T} 1$.

Attachment points of ligaments and muscles on to the cervical vertebrae are described in the literature with respect to anatomical landmarks of the bony geometry such as from the transverse or spinous processes $[\mathbf{8}, \mathbf{9}, \mathbf{1 1}]$. It is therefore helpful to include as many of these geometric features as possible in the construction of the vertebrae.

\subsection{Configuration of the upper cervical spine}

Owing to the anatomical differences of the atlas and axis vertebrae to the other cervical vertebrae the model of the upper cervical spine was developed separately to the lower cervical spine.

The geometric construction of the dens and C1 were based on Schaffler et al. [12], Doherty and Heggeness [13, 14], and Xu et al. [11]. The dimensions used to construct $\mathrm{C} 1$ and $\mathrm{C} 2$ are taken from Panjabi et al. $[\mathbf{8}, \mathbf{9}]$, Xu et al. [11], Doherty and Heggeness [13, 14] and Schaffler et al. [12]. The occiput (C0), or base of the skull was modelled separately to the skull with the two being rigidly fixed. The model of the skull, shown in Fig. 1, was developed based on anthropometric data from a survey of 500 Royal Air Force aircrew heads [15] and from anatomical drawings of the skull [16]. Both skull and occiput share the same origin, with all the physical properties of the head being associated with the occiput, the skull is merely included for visual purposes and for contact to external bodies if required in impact simulation. The occipital condyles are attached to the occiput and all muscle attachments to the skull are positioned and fixed relative to the occiput origin. The centre of gravity and origin of the bodies are based on those described by De Jager [2] including the position of the occipital condyles. The origin of $\mathrm{C} 0$ is positioned at the apparent centre of rotation of $\mathrm{C} 0$ relative to $\mathrm{Cl}$ as described by Kapandji [17] and De Jager [2]. The centre of gravity of the skull is positioned relative to the origin of $\mathrm{C} 0$ as reported by Thunnissen et al. [18].

\subsection{Construction of the entire cervical spine}

The individual vertebrae were constructed as described in Solid Edge 3D CAD software (UGS, Surrey, United Kingdom) before being imported as solid bodies into multi-body dynamic simulation software MSC.visualNastran4D (MSC Software Corporation, California, USA). The vertebrae were each positioned with respect to the global coordinate system with T1 as origin and local coordinate system being in line with and at the origin of the global coordinate system. The global coordinate system was set up with $x$-, $y$-, $z$-axes pointing forward, to the left, and upwards, respectively.

The inertial properties of the neck are lumped into the rigid vertebrae and represent the inertial characteristics of a slice through the neck at each vertebral level containing all surrounding soft tissues. The properties used are those derived by De Jager [2] as shown in Table 1, who calculated the moment of inertia at each level by assuming the straightened neck to be a cylinder made up of seven segments, each with a height equal to the distance between adjacent 
Table 1 Inertial and geometric data for the rigid bodies of the cervical spine (adapted from De Jager [2])

\begin{tabular}{|c|c|c|c|c|c|c|c|c|c|c|}
\hline \multirow[b]{2}{*}{ Name } & \multirow[b]{2}{*}{ Mass (kg) } & \multicolumn{4}{|c|}{$\begin{array}{l}\text { Moments of inertia } \\
\qquad\left(\mathrm{kg} \mathrm{cm}^{2}\right)\end{array}$} & \multicolumn{2}{|c|}{$\begin{array}{l}\text { Origin of local body } \\
\text { coordinate system } \\
\text { expressed in global } \\
\text { coordinates (mm) }\end{array}$} & \multicolumn{2}{|c|}{$\begin{array}{c}\text { Position of centre } \\
\text { of gravity with respect to } \\
\text { local body coordinates } \\
\text { system (mm) }\end{array}$} & \multirow{2}{*}{$\begin{array}{l}\begin{array}{l}\text { Initial } \\
\text { orientation } \\
\text { (deg) }\end{array} \\
\alpha_{\mathrm{y}}\end{array}$} \\
\hline & & $I_{\mathrm{xx}}$ & $I_{\mathrm{yy}}$ & $I_{\mathrm{zz}}$ & $I_{\mathrm{xz}}$ & $X$ & $Z$ & $\operatorname{cg}_{\mathrm{x}}$ & $\mathrm{cg}_{\mathrm{z}}$ & \\
\hline $\mathrm{T} 1$ & & & & & & 0.0 & 0.0 & & & 0.0 \\
\hline $\mathrm{C} 7$ & 0.22 & 2.2 & 2.2 & 4.3 & - & 6.4 & 16.8 & -8.2 & 0.0 & 20.8 \\
\hline C6 & 0.24 & 2.4 & 2.4 & 4.7 & - & 11.1 & 34.7 & -8.3 & 0.0 & 15.2 \\
\hline C5 & 0.23 & 2.3 & 2.3 & 4.5 & - & 12.9 & 52.2 & -8.1 & 0.0 & 10 \\
\hline $\mathrm{C} 4$ & 0.23 & 2.3 & 2.3 & 4.4 & - & 12.7 & 69.8 & -7.9 & 0.0 & 5.3 \\
\hline C3 & 0.24 & 2.4 & 2.4 & 4.6 & - & 10.3 & 87.5 & -7.8 & 0.0 & 0.0 \\
\hline $\mathrm{C} 2$ & 0.25 & 2.5 & 2.5 & 4.8 & - & 7.02 & 106.5 & -7.7 & 0.0 & 0.0 \\
\hline $\mathrm{C} 1$ & 0.22 & 2.2 & 2.2 & 4.2 & - & 7.02 & 123.0 & -7.7 & 0.0 & 0.0 \\
\hline $\mathrm{C} 0$ & 4.69 & 181 & 236 & 173 & 71.0 & 3.02 & 143.0 & 37.0 & 43.0 & 0.0 \\
\hline
\end{tabular}

vertebral body origins. The volume and radius of the cylinder were then calculated by using a total neck mass of $1.63 \mathrm{~kg}$ with an average density of $1170 \mathrm{~kg} / \mathrm{m}^{3}$ as reported by Walker et al. [19] and used to determine the moments of inertia at each vertebral level. The principal moments of inertia are defined parallel to the local body coordinate system of each vertebra originating at the centre of gravity. The centre of gravity of each vertebra lies on the posterior edge of the vertebral body in line with the $x$-axis of the local body coordinate system (Fig. 3). The positions of the centre of gravity of $\mathrm{C} 1-\mathrm{C} 7$ are given in Table 1.

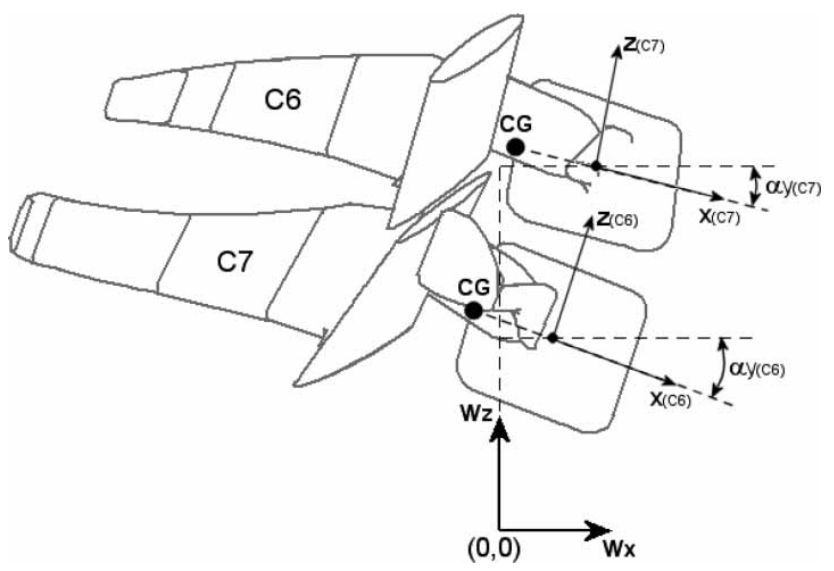

Fig. 3 Schematic showing origin position and local body coordinate system used in the head-neck model. The origin of each vertebra is expressed in global coordinates $(\mathrm{Wx}, \mathrm{Wy}, \mathrm{Wz})$ with rotation about the global $y$-axis $(\alpha y)$. The local coordinate system of each vertebra lies at the centre of the vertebral body with the $x$-axis parallel to the lower endplate of the body. The position of the body's centre of gravity is also shown (cg)

\subsection{Facet joints}

Together with the intervertebral disc, the facet joints resist compressive forces in the cervical spine. The amount of compressive force resisted by the facet joint pair at any cervical level depends on their orientation and on the eccentricity of the external load applied [20]. The coupling motion of the lower cervical spine in lateral bending and axial rotation is also determined by the oblique orientation of the facet joints. The facet surfaces are rigidly attached to the articular processes or their parent vertebrae. The articular facets are covered with a thin layer of cartilage and lubricated with synovial fluid allowing for almost frictionless sliding motion between adjacent facet surfaces [21].

In the model the articular facet surfaces are approximated by a slice off a sphere at a diameter equal to the average of the ellipse diameters reported by Panjabi et al. [9] as an approximation of measured facets surfaces. The height of curvature was taken to be $1 \mathrm{~mm}$ to give a slight curve to the surface of the almost flat facets. Panjabi also presents vertical and lateral distance between the centres of the facet surfaces and the orientation of the facets for vertebrae $\mathrm{C} 2-\mathrm{C} 7$. No position of the facets with respect to the vertebral bodies is given so the method of facet positioning used by De Jager [2] has been adopted. To position the facets with respect to the vertebra it is assumed that the middle of the vertical distance $(h)$ between facet surfaces lies at the same height as the origin of the vertebral body. The facet surfaces are at an equal distance on either side of the vertebra (due to mid-sagittal symmetry) and are positioned posteriorly, at a distance equal to the anterior-posterior radius of the facet surface $(a)$, to the cg of the vertebra. Figure 4 shows the construction of an articular facet (a) and the positioning of the facets with respect to the vertebrae (b). The contact between facets is defined and modelled as frictionless rigid body contact allowing the facets to slide 


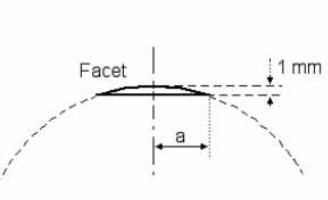

(a)

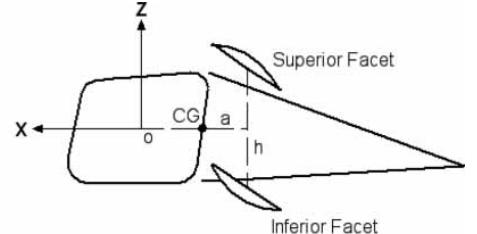

(b)
Fig. 4 Articular facet construction. (a) Construction of facet surface. (b) Position of facet surfaces with respect to the vertebrae

relative to each other without friction approximating the synovial joint behaviour of real facet joints.

\subsection{Atlanto-occipital, atlanto-axial, and atlanto-odontoid joints}

The occipital condyles of the skull are received by the superior articular sockets of the atlas allowing for predominantly nodding movements between the two bodies (Fig. 5). This atlanto-occipital joint creates a large degree of stability due to the concave-convex interaction. The sidewalls of the sockets prevent the occiput form sliding sideways whereas the front to back walls prevent anterior and posterior gliding of the head. The odontoid process of the axis acts as a pivot for the atlanto-axial joint with its convex facet articulating with the concave facet on the anterior arch of the atlas. The two joints work together allowing for a large degree of axial rotation (Fig. 5), moderate flexion and extension and only a small amount of lateral bending.

The facets of the upper cervical spine joints are modelled in a similar manner to those of the lower cervical spine, the atlanto-axial joints being two articulating convex surfaces with dimensions approximated from Panjabi et al. [9] and Tominaga et al. [22]. The C2
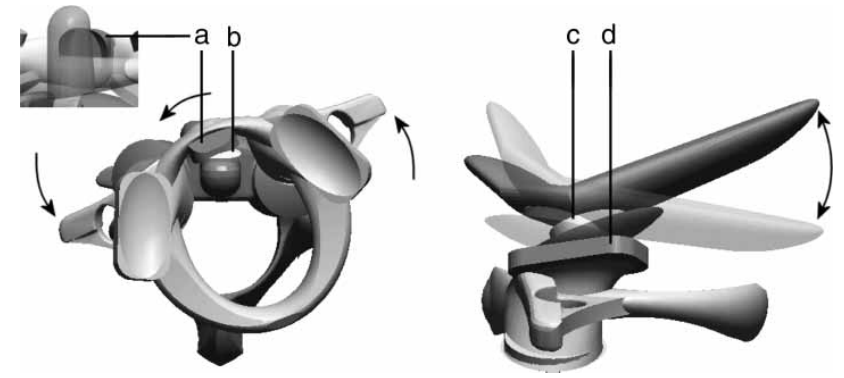

Fig. 5 Upper cervical spine motion. Left: atlanto-axial rotation showing how the anterior arch of the atlas (a) slides around the facet of the dens process (b). Right: flexion and extension of the atlanto-occipital joint showing how the convex occipital condyles (c) move in the concave sockets of the superior facets of the atlas (d) superior facets are rotated about the $x$-axis orientated according to Panjabi et al. [9]. The centre of the dens facet is positioned on the anterior surface of the dens $18.4 \mathrm{~mm}$ above the vertebral origin at an angle of $-13^{\circ}$ to the vertical [14]. The height and width of the facet is approximated from Doherty and Heggeness [14] and $\mathrm{Xu}$ et al. [11]. The anterior facet of the atlas has a corresponding concave curvature with a depth of $1 \mathrm{~mm}$ and is positioned in line with the dens facet and with the same orientation in the initial position. A similar arrangements is used for the atlanto-occipital joints, the inferior facets of the occiput are convex and positioned so they are sat in the concave sockets of the superior facets of $\mathrm{C} 1$ in the initial position. The position and orientation of the superior facets of the atlas are derived from Doherty and Heggeness [13], Kapandji [17], and De Jager [2].

\section{MODELLING INTERVERTEBRAL DISCS}

The intervertebral discs located between the vertebrae of the lower cervical spine resist loads in multiple directions. Under any external loading with the exception of direct uniaxial tension, discs carry compressive forces in association with other components and along with the facets joints are responsible for carrying all the compressive forces the neck is subjected to [21]. The discs are held in some degree of compression during normal physiological motion due to the weight of the head.

The stiffness characteristics of the intervertebral discs are modelled MSC.visualNastran4D as nonlinear viscoelastic 'bushing' constraints in flexion and extension and linear in all other loading directions. They are located at the disc centre located approximately at the centre of the space between the upper and lower end plates of adjacent vertebrae at a fixed distance relative to the centre of the upper vertebrae. A 'bushing' constraint allows all translational and rotational degrees of freedom restricted by spring and damper relationships. There are no discs between the axis, atlas, and occiput.

Material properties of the intervertebral discs are required for multiple directions of loading, i.e. flexion, extension, tension, compression, anterior and posterior shear, lateral shear, axial rotation, and lateral bending. Due to the mid-sagittal symmetry of the cervical spine, disc response can be assumed to be the same for left and right lateral bending, lateral shear, and axial rotation. Vertebral disc responses are obtained by subjecting a motion segment (vertebradisc-vertebra) or a disc segment (body-disc-body) to external loading. Disc stiffnesses reported by Moroney et al. [23] were used along with the tension and compression values presented in Yoganandan et al. [24]. Moroney states that disc stiffnesses were 
Table 2 Biomechanical stiffness and damping data for the intervertebral discs

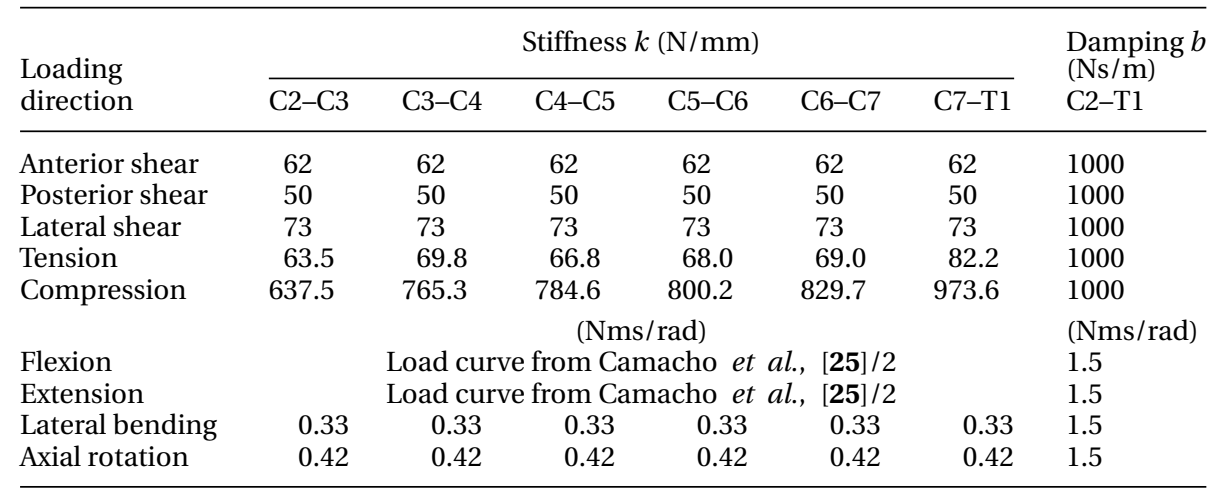

not independent to disc level. However, the stiffness coefficients reported by Yoganandan for compression of cervical discs gradually increase from $637.5 \mathrm{~N} / \mathrm{mm}$ at C2-C3 to $973.6 \mathrm{~N} / \mathrm{mm}$ at C7-T1. As no other data on disc stiffnesses can be found Moroney's values have been used for axial rotation, lateral bending, and all shear stiffness coefficients. A recent study on flexion and extension of the cervical spine presents nonlinear load-displacement curves at various levels [25]. Although the stiffness curves reported represent the response of entire motion segments, with ligaments and facet joints left intact, theses values can still be used to define the flexion/extension response of the disc. From the results of Moroney on intact segments and disc segments it can be seen that approximately half the flexibility of the motion segment is caused by the ligaments and the other half by the disc in flexion and extension. From the intact segment tests it was found that the linear stiffness was 0.43 and $0.73 \mathrm{Nm} / \mathrm{deg}$ for flexion and extension, respectively, whereas for the isolated disc segments the stiffness was found to be 0.21 and $0.32 \mathrm{Nm} / \mathrm{deg}$. It is therefore reasonable to divide the flexion/extension stiffness functions, presented by Camacho et al. [25], by 2 to give the approximate non-linear response of the intervertebral discs. This approach has also been used by Van Der Horst [5].

The translational damping coefficients of the discs are set to $1000 \mathrm{Ns} / \mathrm{m}$ and rotational coefficients to $1.5 \mathrm{Nms} / \mathrm{rad}$ as a preliminary estimation based on those used by De Jager as no actual cervical spine disc damping coefficients have been reported in the literature. These damping coefficients were shown not to account for the dynamic stiffening of the disc but instead were used to attenuate vibration accelerations of the head [2]. In the model, the dynamic stiffness of the disc is assumed to be twice the static stiffness since the response of ligaments can increase 2-5 times when the loading rate increase by a factor of 100-1000 relative to quasi-static loading rate. As the loading rate varies quite a lot in an impact it was assumed that the dynamic stiffness averages twice the static stiffness.
Table 2 summarizes the biomechanical stiffness and damping data for the intervertebral discs.

\section{MODELLING LIGAMENTS}

Ligaments of the neck provide stability to the motion segments allowing motion within physiological limits and absorbing energy during trauma. Ligaments are uniaxial structures that resist only tensile or distractive forces becoming slack in compression.

Data from Panjabi et al. $[\mathbf{8}, 26]$ were used in determining the dimensions and attachment points of the cervical spine ligaments. Six ligaments of the lower cervical spine are included at each level: anterior and posterior longitudinal ligament (ALL and PLL), flava ligament (FL), interspinous ligament (ISL), and the left and right capsular ligaments. Seven ligaments of the upper cervical spine are included in the model: apical ligament, transverse ligament, left and right alar ligaments, tectorial membrane, anterior and posterior membranes, and the left and right capsular ligaments.

Due to the large diameters of the facet surfaces of the atlanto-axial joint the capsular ligaments are represented by four spring elements positioned around the perimeter of the facet joints. Three spring elements represent the capsular ligaments of each atlanto-occipital facet joint, one positioned in the centre in a similar manner to the capsular ligaments of the lower cervical spine and one at either edge of the large diameter of the facet surfaces (Fig. 6).

The ligaments are modelled as non-linear viscoelastic spring elements in VisuaNastran4D. The non-linear force-deflection curves presented by Yoganandan et al. [27] for lower cervical spine ligaments (C2-T1) are used to define load curves for ligament response. The curves are described in look-up tables in visuaNastran4D with the elements defined as being active for positive values of deflection only, producing force in tension only. The ligaments' rest lengths are defined as the element lengths in the 


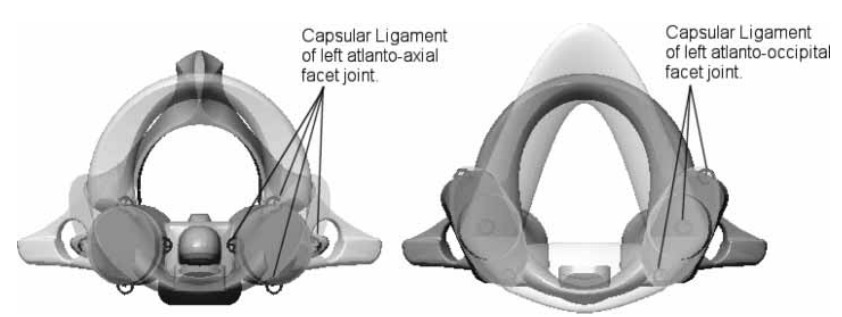

Fig. 6 Arrangement of spring elements representing the capsular ligaments of the upper cervical spine

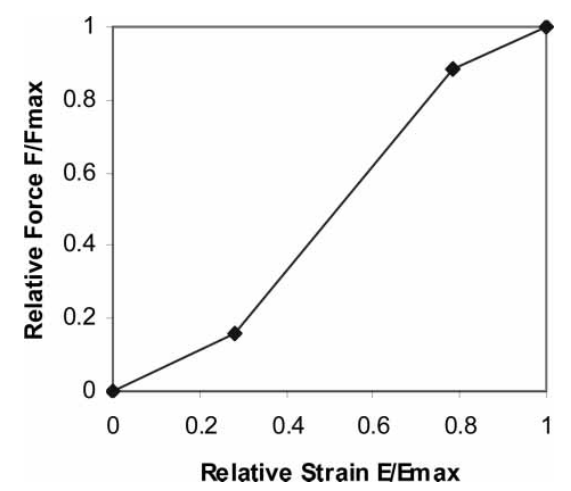

Fig. 7 Average dimensionless force-strain curve used to define force-deflection curves for the upper cervical spine ligaments. The strain relative to the strain at failure $\left(E_{\max }\right)$ is given along the horizontal axis and the force relative to the force at failure $\left(F_{\max }\right)$ is given along the vertical axis

initial body posture. The results reported by Yoganandan are from tests on in situ cervical ligaments where the internal load balance due to initial ligament tension is maintained and so the force deflection curves represent the ligament response starting from their initial prestress reducing the toe-region of the curves.
This should give the motion segment greater stability in its initial configuration.

No force-deflection curves have been characterized for the ligaments of the upper cervical spine although Yoganandan et al. [24] have presented failure force and deformation for each. Chazal et al. [28] defined the non-linear force-strain behaviour of ligaments from the thoracic and lumbar spine including a few from the lower cervical region. The average dimensionless force-strain curve, normalized relative to the failure force $F_{\max }$ and failure strain $E_{\max }$, for all ligaments tested by Chazal et al. is shown in Fig. 7. This curve demonstrates that spinal ligaments exhibit almost identical behaviour in dimensionless form and so the curve can be used together with measured failure force and deformation to characterize the non-linear response of any specific spinal ligament. Here the curve has been used together with the force and deformation at failure, presented in Yoganandan et al. [24], to define the non-linear forcedeflection curves for each of the ligaments of the upper cervical spine.

The viscous behaviour of the ligaments is represented by a constant damping coefficient of $300 \mathrm{~kg} / \mathrm{s}$ as used by De Jager as an arbitrary starting value.

General views of the ligaments cervical spine model is shown in Fig. 8 illustrating complete neck model and upper and lower segments.

\section{MODELLING MUSCLES}

In the head-neck model muscles are included to investigate the effect of muscle forces on the behaviour of the head and neck response to impact. There are an immense number of muscle groups acting on the cervical region of the spine. Many of these muscles cross two or more vertebral pairs as they span between multiple sites of attachment, as can be seen
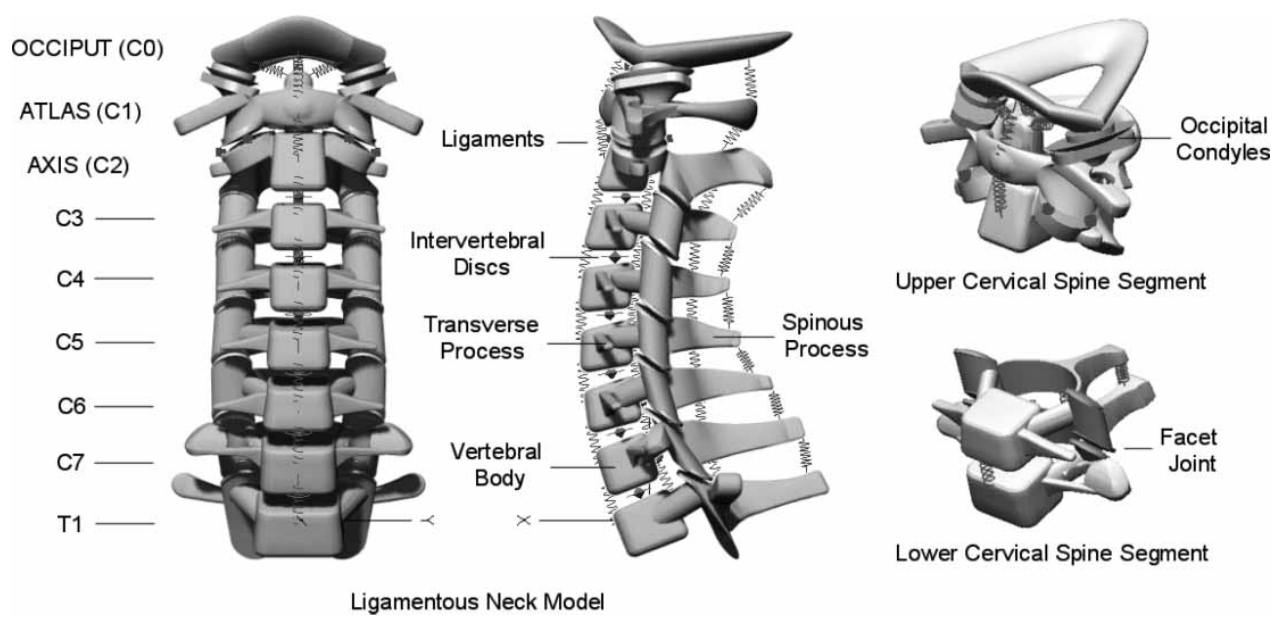

Fig. 8 Ligaments cervical spine model. General views showing complete neck model and upper and lower segments 


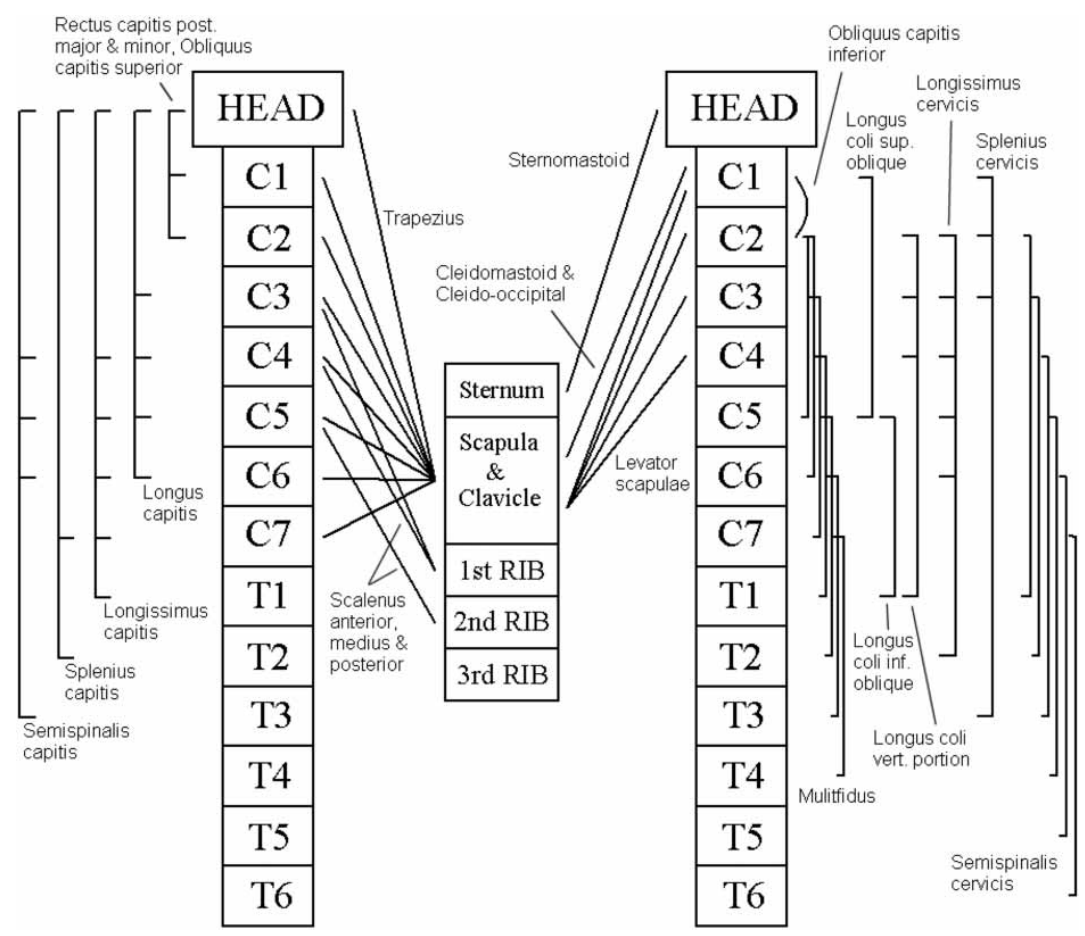

Fig. 9 Muscle map of neck muscles included in the head-neck model, showing points of attachment origins and insertions

in the schematic muscle map shown in Fig. 9. It is therefore necessary to simplify these muscles, group them and consider only those that contribute most to the stability of the head and control of the neck. Muscle parameters are based on a detailed study of neck muscle morphometry and fibre type composition of each of the muscles groups. For this reason 18 muscle groups with broad areas of attachment are subdivided into a number of individual muscle elements resulting in 69 individual muscle segments on each side of the body. Muscle attachment sites were chosen based on published anatomic descriptions and data.

\subsection{Virtual muscle}

Muscle mechanics is handled by an external application called Virtual Muscle 3.1.5 developed at the Alfred E. Mann Institute at the University of Southern California LA, CA, USA that runs within Matlab and Simulink. Virtual Muscle has been created to provide realistic muscle properties to control the muscle activation and drive the skeletal dynamics that are in turn handled by visuaNastran4D.

The total length of each chain of connected actuators representing the individual muscle elements is read from VisuaNastran4D at each time step of simulation and passed to Simulink as the input for musculotendon path length. This along with level of activation is used to calculate the muscle force, which in turn is passed back to the head-neck model.
Virtual Muscle has been created to be used in the context of a hierarchical model of motor control with itself occupying the middle layer (Fig. 10). Realistic muscle properties provided by Virtual Muscle drive the skeletal dynamics that are in turn handled by MSC.visualNastran4D comprising the lowest level of the system. At the top-level, muscle activation is controlled. The basic form of the muscle model is generally similar to those of Hill [29] and Zajac [30]. Complete descriptions of the main elements of the

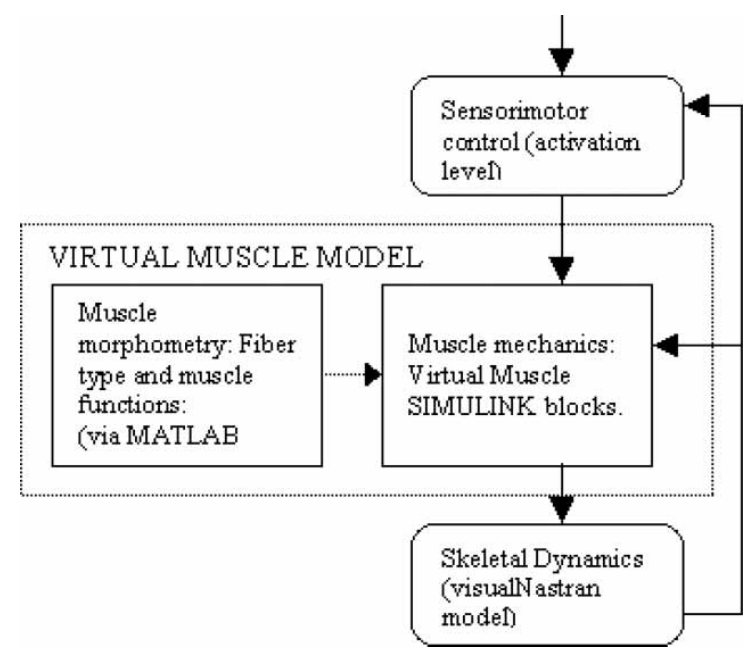

Fig. 10 Flow diagram showing the order of muscle control 
model can be found in Brown and Loeb [31] and Brown et al. [32].

\subsection{Defining muscle fibre types}

Zajac [30] showed that the behaviour of the contractile element of muscle scales well from the sarcomere level up to the whole muscle fibre and again up to the level of an entire recruitment group of motor units. By defining the properties of each fibre type that will be used throughout the muscle model in a single database, allows the muscle model to reference these properties when fibre types are combined in varying percentages to form a typical mixed-fibre type muscle. For the purpose of this study the generic fasttwitch and typical-slow twitch fibre types derived for human muscles as presented in Cheng et al. [33] are used (Table 3 for specific fibre type best-fit constants and associated equations). The parameters used to define these fibre types are presented in Table 4 . The optimal sarcomere length of $2.7 \mu \mathrm{m}$ was taken from Herzog et al. [34], which is in close agreement with the value of $2.8 \mu \mathrm{m}$ reported in another study by Rack and

Table 3 Equations and coefficients for 'Virtual Muscle' muscle model

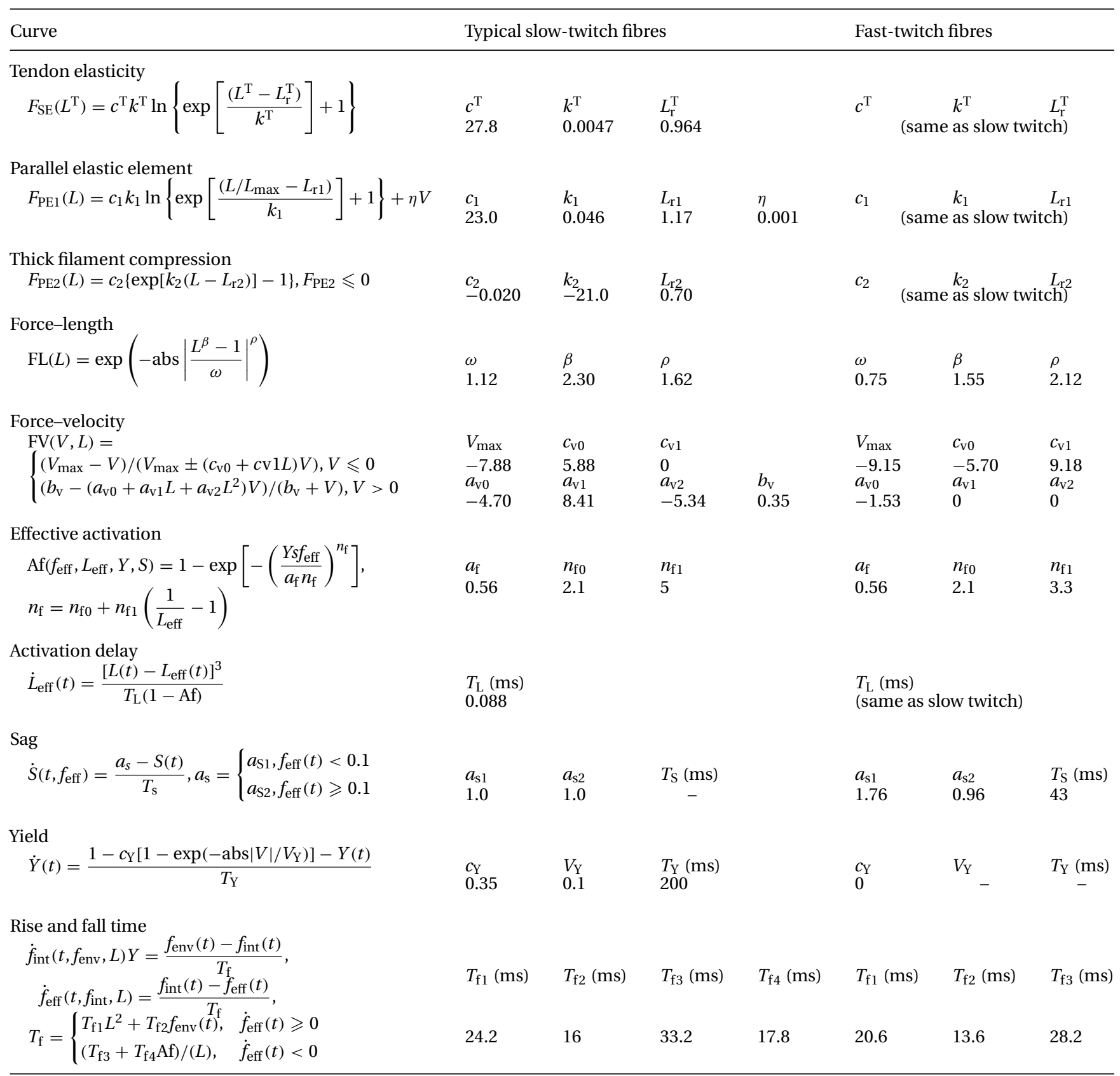

Extrapolated parameters for human skeletal muscle fibre types and associated model equations [33]. 
Table 4 Muscle model fibre type parameters

\begin{tabular}{lll}
\hline & $\begin{array}{l}\text { 'Typical' } \\
\text { slow-twitch } \\
\text { fibre type }\end{array}$ & $\begin{array}{l}\text { Generic } \\
\text { fast-twitch } \\
\text { fibre type }\end{array}$ \\
\hline $\begin{array}{l}\text { Opibre type parameter } \\
\text { length }(\mu \mathrm{m})\end{array}$ & 2.7 & 2.7 \\
$\begin{array}{l}\text { Recruitment rank } \\
V_{0.5}\left(L_{0} / \mathrm{s}\right)\end{array}$ & 1 & 2 \\
$\begin{array}{l}f_{0.5}(\mathrm{pps}) \\
\begin{array}{l}\text { Specific tension } \\
\left(\mathrm{N} / \mathrm{cm}^{2}\right)\end{array}\end{array}$ & -1 & -1.67 \\
\hline
\end{tabular}

Westbury [35]. This value is used to scale the active and passive force-length properties. The recruitment rank defines which fibre type is recruited first in a muscle composed of more than one fibre type. $V_{0.5}$ is the shortening velocity required to produce half the maximum tetanic force $\left(0.5 F_{0}\right)$ at $1.0 L_{0}$ (fascicle length at which $F_{0}$ is elicited). The frequency at which half of maximal tetanic force, $f_{0.5}$, is obtained (isometric at $\left.1.0 L_{0}\right)$, scales the rise and fall times. For details of how $V_{0.5}$ and $f_{0.5}$ were obtained the reader is referred to Cheng et al. [33].

The specific tension is defined as the maximal isometric force produced at the optimal length per unit cross-sectional area. As a starting point the default value of $31.8 \mathrm{~N} / \mathrm{cm}^{2}$ has been used based on Scott et al. [36] and Brown et al. [37]. However, the value has been estimated to be anywhere between 20 and $100 \mathrm{~N} / \mathrm{cm}^{2}$ by Winters and Stark [38] and it is hypothesized that a higher value than $31.8 \mathrm{~N} / \mathrm{cm}^{2}$ may be required to truly represent the maximum muscular forces that can be exerted by a human subject and that the value of specific tension is likely to vary between subjects due to gender differences and different levels of muscular development.

\subsection{Defining muscle morphometry}

The parameters required for the muscle model that are independent of fibre type and specific to individual muscles are $F_{0}, L_{0}, L_{0}^{\mathrm{T}}$, and $L_{\max } . L_{0}$ is the muscle fibre length at peak isometric active muscle force, $F_{0}$ ( $L_{0}$ and $F_{0}$ are specific to the muscle fascicles). $L_{0}^{\mathrm{T}}$ is the length of muscle tendon at maximal tetanic isometric force and differs from the more commonly used tendon slack length $\left(L_{S}^{\mathrm{T}}\right)[\mathbf{3 0}] . L_{S}^{\mathrm{T}}$ is less well defined than $L_{0}^{\mathrm{T}}$ and tends to be around 5 per cent shorter $[\mathbf{3 3}] . L_{\max }$ is the length of the muscle fascicles at the maximal anatomical length of the muscle.

The morphometric values required for the model are muscle mass, optimal fascicle length, optimal tendon length, and the maximal anatomical musculotendon path length. These measures are then used either directly or to calculate the required parameters of the models equations. Optimal fascicle length and optimal tendon length correspond directly to $L_{0}$ and $L_{0}^{\mathrm{T}}$. Muscle mass and fascicle length are used to derive the physiological cross-sectional area (PCSA) of the muscle, which is proportional to $F_{0} \cdot L_{\max }$ is calculated from the difference of the maximum whole-muscle length and the tendon $L_{0}^{\mathrm{T}}$, scaled by muscle fascicle length $L_{0}$.

Mass and optimal fascicle length of most neck muscles have been reported by Kamibayashi and Richmond [39]. The muscle fascicle lengths reported were used for each of the subelements of a given muscle. Muscle mass was either divided equally between the subvolumes or proportionally so as to give the required PCSA of the individual elements and the overall muscle. Optimal tendon length was approximated by using 105 per cent of tendon slack length [40]. Tendon slack length was calculated as the difference between the musculotendon length at the neutral head position of the model and the muscle fascicle length, Kamibayashi and Richmond state that the measured muscle fascicle length in the neutral posture are within 15 per cent of their optimal length. Values of maximal musculotendon path length have been chosen based on the path length of the muscle elements in the head-neck model at extreme positions of the head so as to give values of $L_{\max }$ between 1.1 and $1.42[\mathbf{4 0}]$.

Once the specific morphometry of an individual muscle has been established the muscle must be apportioned to the relevant muscle fibre types. The histochemical composition of most neck muscles has been reported in the literature, Table 5 shows the fibre type distribution for the neck muscles included in the model along with the source of reference. Finally the number of motor units that is to be used to simulate each fibre type in the muscle is specified. Normally a muscle has about 100 or more motor units. Although it is possible to create such a detailed muscle model with Virtual Muscle, for the head-neck model where a large amount of muscles are being simulated, this resolution would make the model run very slowly and is not necessary. Here a small number of motor units are used where each unit represents a group of 'real' motor units. For example, the Splenius Capitis consists of 37 per cent slowand 63 per cent fast-twitch muscle fibres, with three motor units allocated to the slow-twitch portion and five motor units to the fast-twitch portion of the muscle.

\subsection{Musculotendon blocks}

Once fibre types have been selected and the morphometry of the individual muscle volumes and subvolumes defined the stand-alone Simulink muscle blocks can be created. In total for the head-neck 
Table 5 Histochemical composition of muscle fibre types in the muscles of the head-neck model

\begin{tabular}{|c|c|c|c|}
\hline \multirow[b]{2}{*}{ Muscle name } & \multicolumn{2}{|c|}{$\begin{array}{l}\text { Fibre type distribution(\%)/ } \\
\text { number of motor units }\end{array}$} & \multirow[b]{2}{*}{ Reference } \\
\hline & Slow-twitch & Fast-twitch & \\
\hline \multicolumn{4}{|l|}{ Suboccipital } \\
\hline Rectus capitis post. major & $60 / 4$ & $40 / 3$ & {$[60]$} \\
\hline Rectus capitis post. minor & $60 / 4$ & $40 / 3$ & {$[60]$} \\
\hline Obliquus capitis superior & $50 / 3$ & $50 / 3$ & {$[60]$} \\
\hline Obliquus capitis inferior & $30 / 2$ & $70 / 4$ & {$[60]$} \\
\hline Longissimus capitis & $33 / 2$ & $67 / 4$ & {$[61]$} \\
\hline Longissimus cervicis & $45 / 3$ & $55 / 3$ & {$[61]$} \\
\hline Splenius capitis & $37 / 2$ & $63 / 4$ & {$[61]$} \\
\hline Splenius cervicis & $50 / 3$ & $50 / 3$ & {$[60]$} \\
\hline Semispinalis capitis & $35 / 2$ & $35 / 4$ & {$[61]$} \\
\hline Semispinalis cervicis & $35 / 2$ & $35 / 4$ & {$[61]$} \\
\hline \multicolumn{4}{|l|}{ Scalenus } \\
\hline Scalenus anterior & $29 / 2$ & $71 / 4$ & {$[61]$} \\
\hline Scalenus medius & $29 / 2$ & $71 / 4$ & {$[61]$} \\
\hline Scalenus posterior & $29 / 2$ & $71 / 4$ & {$[61]$} \\
\hline \multicolumn{4}{|l|}{ Sternocleidomastoid } \\
\hline Sternomastoid & $23 / 2$ & $77 / 4$ & {$[61]$} \\
\hline Cleidomastoid & $23 / 2$ & $77 / 4$ & {$[61]$} \\
\hline Cleido-occipital & $28 / 2$ & $72 / 4$ & {$[61]$} \\
\hline Trapezius & $26 / 2$ & $74 / 4$ & {$[61]$} \\
\hline Longus colli & $54 / 3$ & $46 / 3$ & {$[62]$} \\
\hline Longus capitis & $40 / 3$ & $60 / 4$ & $\begin{array}{l}\text { Estimated. Not present } \\
\text { in the literature }\end{array}$ \\
\hline Levator scapulae & $26 / 2$ & $74 / 4$ & $\begin{array}{l}\text { Estimated. Not present } \\
\text { in the literature }\end{array}$ \\
\hline Multifidus & $77 / 4$ & $23 / 2$ & {$[62]$} \\
\hline
\end{tabular}

model there are 69 unique muscle blocks each repeated for the left and right symmetrical muscle elements. Each musculotendon block requires inputs for activation and for musculotendon path length. The output from the musculotendon element is force in newtons. A schematic of the Simulink model for the Splenius Capitis is shown in Fig. 11.

It is assumed here that the activation input of a muscle is determined by a single neural input where the level of activation lies between 0 and 1, 0 for passive muscle and 1 for maximally activated muscle.

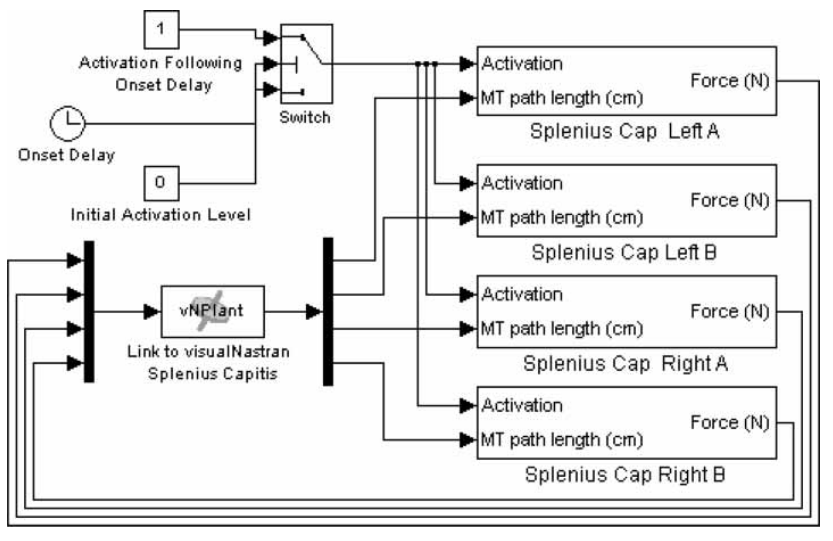

Fig. 11 Simulink model for the Splenius capitis muscle group. The switch is used to change the level of activation following a specified onset delay
For muscle activation it is assumed that the level of activation changes instantaneously from 0 to 1 after a certain onset/reflex delay. Reflex time is defined as the time it takes to start activating a muscle in reaction to an external disturbance, which in the case of a motor vehicle collision may be a visual signal, a loud noise, or impact induced motion. Reported reflex times for neck muscles range from 25 to $90 \mathrm{~ms}$ [41-44].

\subsection{Muscle attachment}

The positions of the muscle attachments are important in controlling the movement of the head and neck. Hence the cervical vertebrae have been modelled in detail to include the bony anatomy that facilitates the location of attachment points of the muscle tendons. The three main areas of muscle attachment are to the tip of the spinous process, the tip of the transverse process, and to the anterior tubercle of the transverse process. Due to T1 being the lowest vertebra included in the model, muscles whose attachment sites lie beneath $\mathrm{T} 1$ attaching on lower thoracic vertebrae or to other bony anatomy such as the clavicle or scapula are fixed with respect to T1, positioned at their appropriate anatomical locations. This ensures realistic muscles lengths and more accurate muscle lines of action. 
Each muscle group included in the head-neck model were attached to the correct anatomical position in space and morphometric values of the muscle elements were used to represent the various muscle volumes. These muscle groups, schematically shown in Fig. 9, include Flexors (Longus capitis, Longus colli, Scalenus, Sternocleidomastoid) and Extensors (Levator scapulae, Longissimus capitis, Longissimus cervicis, Multifidus, Semispinalis capitis, Semispinalis cervicis, Splenius, Suboccipital muscles, Trapezius).

Morphological parameters of muscles, anatomical data, sites of attachment, and insertion points on the cervical spine and skull have been obtained from published data available in the literature. These include Gray [16], Adam-Rouilly [45], Gurumoorthy and Twomey [46], Kamibayashi and Richmond [39], Warfel [47], Kapandji [17], and Johnson et al. [48]. When there was no morphological data available, values estimated by Vasavada et al. [49], Van Der Horst et al. [50], Van Der Horst [5], and De Jager [2], have been used.

\subsection{Curving and force application}

In addition to the origins and insertions each muscle element passes through a series of predefined intermediate points to simulate the curving of the muscle around the vertebrae and soft tissues of the neck during neck bending. This curved musculature is modelled by a chain of connected actuators resulting in a more realistic representation of the change in muscle length during head-neck motion.

Individual muscle elements that span more than one of the cervical vertebrae are represented by a chain of connected actuators leading from the point of origin to insertion to allow curving of the muscle around the vertebrae. In the initial upright head-neck position each muscle element is straight, connecting origin to insertion, a series of intermediate points are positioned on the local $x-y$ plane of each successive vertebrae that the muscle spans (Fig. 12(a)). Actuators connect adjacent points to form the muscle; it is the combined length of this chain of actuators that gives the overall length of the muscle that is used to calculate muscle force. As the neck bends the intermediate points stay fixed to their respective vertebrae and so force the chain of actuators to bend around the vertebrae (Fig. 12(b)) resulting in the new overall length of the muscle. The resulting muscle force is applied at both the origin and insertion of the muscle element in the direction of the first and last actuators, effectively at a tangent to the curve of the muscle (Fig. 12(b)). Figure 13 shows the final head and neck model with all the muscle elements in place.

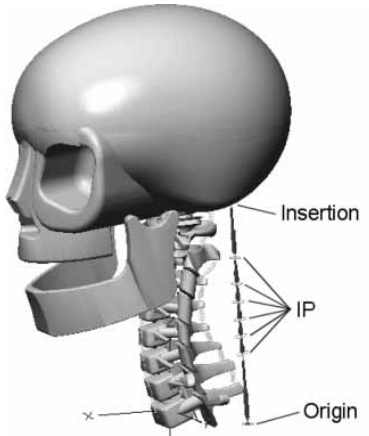

(a)

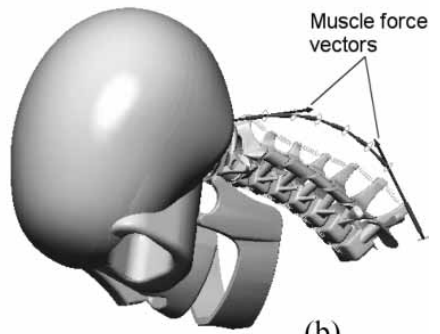

(b)
Fig. 12 Muscle curving, (a) Muscle element in initial position showing the chain of actuators from origin to insertion with intermediate points (IP) (b) Head and neck in flexed position demonstrating the curving of the muscle and showing the direction of the applied muscle force
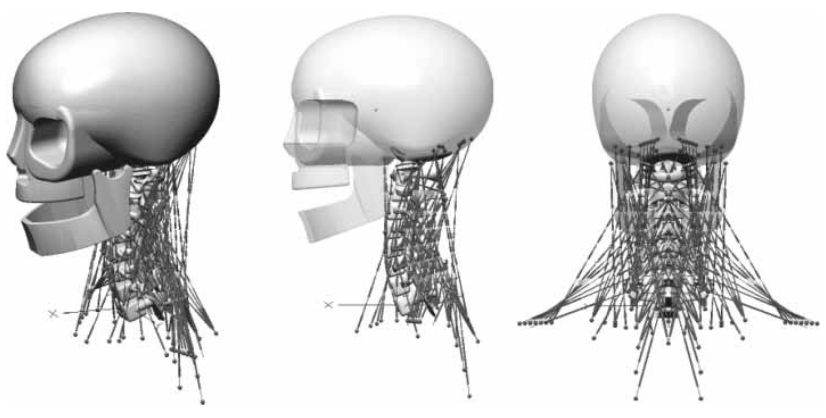

Fig. 13 Isometric, lateral, and rear view of the final head-neck model with all muscle elements in place. The skull shown transparent in lateral and rear view to show attachments points of muscle elements

\section{VALIDATION}

\subsection{Motion segment response}

The objective of this investigation, prior to dynamic response validation, is to show the model's biofidelity at each stage of construction to give confidence in the response of the individual model components by validating the individual motion segment response with experimental data. The lower and upper cervical spine motion segment models are validated by comparing the segment response to published experimental data on the load-displacement behaviour of cervical spine motion segments for both small and large static loads, this approach to model validation was first employed by De Jager [2] in the validation of a less complex multi-body model of the neck. The response of the entire ligamentous cervical spine model to quasistatic flexion and extension loading is also compared to experimental data to validate the head-neck model 
before the effect of muscle stiffening is included. The model then is dynamically validated, which will be the subject of a companion paper [51].

\subsubsection{Motion segment response to small loads}

The response of the motion segments of the lower cervical spine are compared to the experimental results reported by Moroney et al. [23] who tested anatomically complete segments comprising the two adjacent vertebrae, disc, facet joints and ligaments, and 'disc segments' where just the vertebral bodies and intervertebral disc were left. Here the 'intact segment' response is used to validate the response of a complete model motion segment for all loading directions. For load-displacement testing, each motion segment was mounted so that the inferior vertebra was rigidly fixed whereas the superior vertebra was free to move in response to the applied loads. The motion segments were subjected to small static loads of $20 \mathrm{~N}$ and $1.8 \mathrm{Nm}$ in all three directions; the resulting threedimensional displacements were measured at the geometric centre of the upper vertebra. For simulating the segment tests, the model motion segments are set up in an identical manner.

The model of the upper cervical spine, atlas, axis, and occiput, is validated against the experimental results reported by Panjabi et al. $[\mathbf{1 0}, \mathbf{5 2}, \mathbf{5 3}]$ and Oda et al. $[\mathbf{5 4}, \mathbf{5 5}]$ who subjected upper cervical spine specimens to static moments of $1.5 \mathrm{Nm}$ and measured the main and coupled rotations. In these experiments C2 was fixed while moments were applied to the occiput and the corresponding rotations, both main and coupled, were measured at the centres of $\mathrm{Cl}$ and C0. Coupled translations have been reported by Oda et al. [54] measured at two specific mid-sagittal points on $\mathrm{C} 0$ and $\mathrm{Cl}$. One point was located at the anterior edge of the foramen magnum of the occiput and another at the anterior ring of the atlas. Experimental data on the translational loading response of the upper cervical spine motion segments is not available in the literature and so validation is not possible.

The simulation set-up is the same as for the experiments; C2 is anchored while $\mathrm{C} 1$ and $\mathrm{C} 0$ are left free to move in all directions. Loads are applied via an external torque $(1.5 \mathrm{Nm})$ or force $(20 \mathrm{~N})$ to the centre of the occiput and corresponding main and coupled displacements measured. For all simulations an acceleration field of $-9.81 \mathrm{~m} / \mathrm{s}^{2}$ in the $z$-axis was included to simulate the effect of gravity.

Motion segment models C5-C6 and C3-C4 were chosen as representative segments of the lower cervical spine. These two spinal units have very different facet orientations: the facets of C5-C6 point backwards and outwards whereas the facets of C3-C4 point backwards and inwards. The segments also have different ligament stiffness and different flexionextension disc properties.

\subsubsection{Motion segment response to large loads}

In the second stage of validation, the motion segments were subjected to much larger loads to determine their load-displacement curves for all directions. Incremented loads were applied up to a maximum of $500 \mathrm{~N}$ for translational loading and $20 \mathrm{Nm}$ for rotational loading. Loads were applied slowly to minimize the effects of damping and thus provide the elastic response of the segments. The vertebral rotations of the segments are compared to the in vivo ROM presented by White and Panjabi [21].

\subsection{Ligamentous cervical spine response}

The next step was to validate the entire ligamentous cervical spine model before any musculature was included. This step of the validation process follows the procedure described by Van Der Horst [5], who used the experimental results of Camacho et al. [25] to validate an extension of the De Jager [2] multi-body model in the software package MADYMO. Camacho et al. [25] published quasi-static flexion-extension characteristics of ten human cadaveric ligamentous cervical spine specimens (the skull was also left attached during testing). For testing the specimens were turned upside down and fixed in a loading frame. The skull was fixed while pure moments were applied to $\mathrm{T} 1$ up to $1.5 \mathrm{Nm}$ for both flexion and extension in $0.1 \mathrm{Nm}$ increments. The vertebral displacements were measured at each load step to produce detailed load-displacements curve for each level of the cervical spine. Due to difficulties in visualising $\mathrm{Cl}$ during the tests, the upper cervical spine complex was treated as a single motion segment.

To simulate these tests with the cervical spine model the gravitational field was inverted and the skull of the model was rigidly anchored in space. An external torque was applied to the geometric centre of $\mathrm{T} 1$ and incremented in $0.1 \mathrm{Nm}$ steps for both flexion and extension. The sagittal plane rotational displacements were measured at each load increment to produce a directly comparable load-displacement curve for each level of the ligamentous cervical spine model.

\subsection{Coupling characteristics of the head-neck model}

In the lower cervical spine there are two characteristic coupling motions present due to the orientation of the facet joints. First, flexion is coupled with anterior shear and extension with posterior shear. Second, lateral bending is coupled with axial rotation and visa versa $[\mathbf{2 1}, \mathbf{5 6}, \mathbf{5 7}]$. 
Table 6 Comparison of neck muscle moments

\begin{tabular}{|c|c|c|c|c|c|}
\hline Study & $\begin{array}{l}\text { No. and } \\
\text { gender of } \\
\text { subjects }\end{array}$ & $\begin{array}{l}\text { Extension } \\
\text { moment } \\
(\mathrm{Nm})\end{array}$ & $\begin{array}{l}\text { Flexion } \\
\text { moment } \\
(\mathrm{Nm})\end{array}$ & $\begin{array}{l}\text { Axial } \\
\text { rotation } \\
\text { moment } \\
(\mathrm{Nm})\end{array}$ & $\begin{array}{l}\text { Lateral } \\
\text { bending } \\
\text { moment } \\
(\mathrm{Nm})\end{array}$ \\
\hline $\begin{array}{l}\text { Harms-Ringdahl and } \\
\text { Schuldt [63] }\end{array}$ & $10 \mathrm{~F}$ & 29 & & & \\
\hline \multirow[t]{2}{*}{ Jordan et al. $[\mathbf{6 4}]$} & $50 \mathrm{M}$ & $55(14)$ & $21(8)$ & & \\
\hline & $50 \mathrm{~F}$ & 48 (15) & $19(4)$ & & \\
\hline $\begin{array}{l}\text { Mayoux-Benhamou } \\
\text { et al. }[\mathbf{6 5}]\end{array}$ & $5 \mathrm{M}, 10 \mathrm{~F}$ & $53(12)$ & & & \\
\hline Queisser et al. [66] & $12 \mathrm{M}$ & $60(9)$ & & & \\
\hline \multirow[t]{2}{*}{ Vasavada et al. $[\mathbf{5 8}]$} & $11 \mathrm{M}$ & $52(11)$ & $30(5)$ & $15(4)$ & $36(8)$ \\
\hline & $5 \mathrm{~F}$ & $21(12)$ & $15(4)$ & $6(3)$ & $16(8)$ \\
\hline Head-neck model & - & - & 17 & 19 & 39 \\
\hline
\end{tabular}

Mean (and standard deviation where available). M, males; F, females.

\subsection{Moment-generating capacity of muscles}

To validate the muscles of the model the total moment-generating capacity of the neck muscle elements are compared to those found experimentally using human volunteers. Vasavada et al. [58] have presented the most complete study of the three-dimensional moment-generating capacity of the muscles of the head and neck region to date. 11 men and 5 women volunteers with mean age of 31 years were asked to produce maximum head force in extension, flexion, lateral bending, and axial rotation in an upright sitting position with shoulders and torso restrained. The measured forces in each direction were used to calculate the moments about the base of the neck for each of the loading directions. The results of this study as well as those from a number of other studies (Table 6) are used to validate the muscle elements of the head-neck model.

\subsection{Isometric muscle strength}

The isometric strength of the neck muscles was simulated by activating each muscle group maximally while anchoring the rigid bodies of the model in their initial position. Moments were then resolved about the $\mathrm{T} 1$ anatomical coordinate system to calculate the moment-generating capacity of each muscle element about the three axes of revolution. The moments generated are in flexion and extension (force generated by muscles on both sides of the neck), and axial rotation and lateral bending (force generated on one side only).

\section{RESULTS}

\subsection{Motion segment response to small loads}

Figure 14 shows the main and coupled displacements of $\mathrm{C} 5-\mathrm{C} 6$ and $\mathrm{C} 3-\mathrm{C} 4$ in response to $1.8 \mathrm{Nm}$
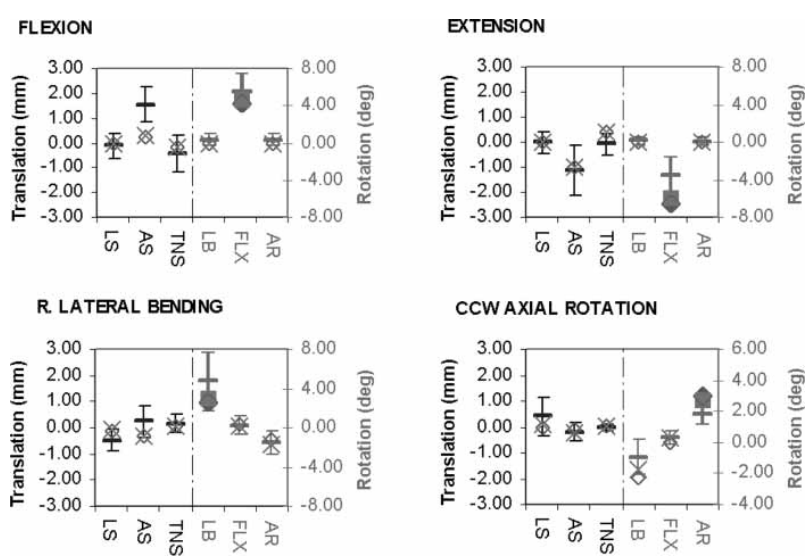

Fig. 14 Main and coupled displacements of model motion segments C3-C4 $(x)$ and C5-C6 ( $)$ in response to applied rotational loads of $1.8 \mathrm{Nm}$ shown against the experimental results (average $\pm \mathrm{SD}$ ) of Moroney et al. [23]. Main rotations are shown as a solid square $(\mathrm{C} 3-\mathrm{C} 4, \mathbf{\square})$ and solid diamond (C5-C6, ). Labels: anterior shear $(+\mathrm{AS})$, posterior shear $(-\mathrm{AS})$, left lateral shear $(+\mathrm{LS})$, right lateral shear $(-\mathrm{LS})$, tension (+TNS), compression (-TNS), right lateral bending $(+\mathrm{LB})$, left lateral bending $(-\mathrm{LB})$, flexion $(+\mathrm{FLX})$, extension $(-\mathrm{FLX})$, left axial rotation $(+\mathrm{AR})$ and right axial rotation $(-\mathrm{AR})$

for flexion, extension, right lateral bending, and CCW axial rotation. Figure 15 shows the segments response to translational loading of $20 \mathrm{~N}$ for anterior shear, posterior shear, right lateral shear, and compression. Each graph shows the main and coupled translations and rotations in response to the specific loading direction. The segment responses are plotted against the mean \pm 1 SD response reported by Moroney et al. [23], no data was available for the motion segment response in tension.

All main displacements and rotations are within $1 \mathrm{SD}$ of the mean reported value except for axial 

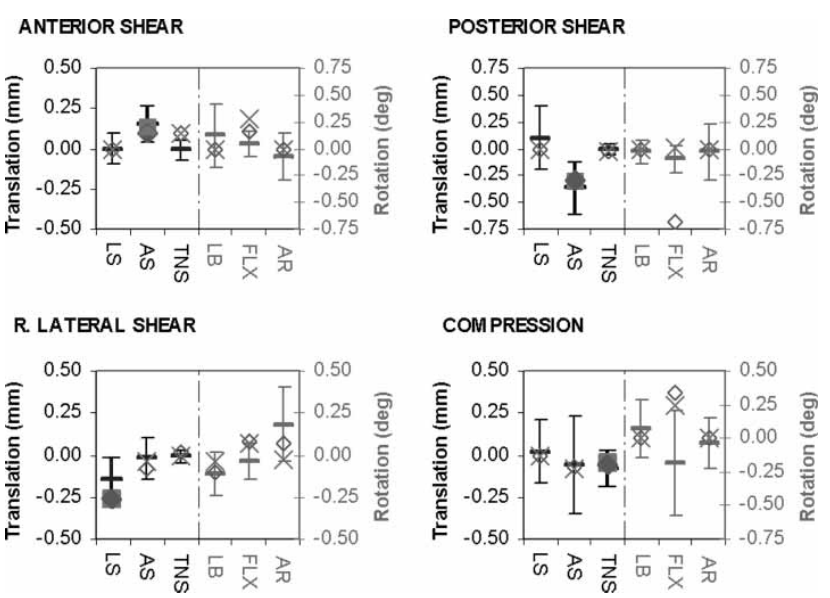

Fig. 15 Main and coupled displacements of model motion segments C3-C4 $(\times)$ and C5-C6 $(\diamond)$ in response to applied translational loads of $20 \mathrm{~N}$ shown against the experimental results (average $\pm \mathrm{SD}$ ) of Moroney et al. [23]. Main rotations are shown as a solid square (C3-C4, घ) and solid diamond (C5-C6, $)$

rotation where both segments appear slightly too flexible. Generally the coupled displacements and rotations are in good agreement with Moroney et al.'s [23] data but a couple of responses differ significantly to the experimental data. In flexion loading both segment models exhibit little anterior shear in comparison to the reported mean, this is due to the facet positioning and orientation. The facets of the lower segments face backward at approximately $45^{\circ}$ and because they have been positioned so they are just touching in the initial position they appear to prevent the coupled anterior translation in response to flexion. Both models appear slightly too flexible in axial rotation and subsequently their coupled response in lateral bending exceeds the reported mean and SD. Generally there is very little difference in response between the two segment models when subjected to small loads.

Figure 16 shows the main and coupled displacements of $\mathrm{C} 0-\mathrm{C} 1$ and $\mathrm{C} 1-\mathrm{C} 2$, respectively, in response to rotational loading. The model results are plotted against the experimental results of Panjabi and coworkers (average \pm SD). In both figures the response to each rotational loading direction, flexion, extension, lateral bending, and axial rotation, are shown on a separate graph. The responses in all directions, main and coupled are shown along the horizontal axis. The magnitudes of the translation (left side) or rotation (right side) are plotted on the vertical axis.

The main displacements of $\mathrm{C} 0-\mathrm{C} 1$ are all with 1 SD of the reported experimental values and lie close to the average for flexion, extension, and lateral bending. Coupled responses are also in good agreement
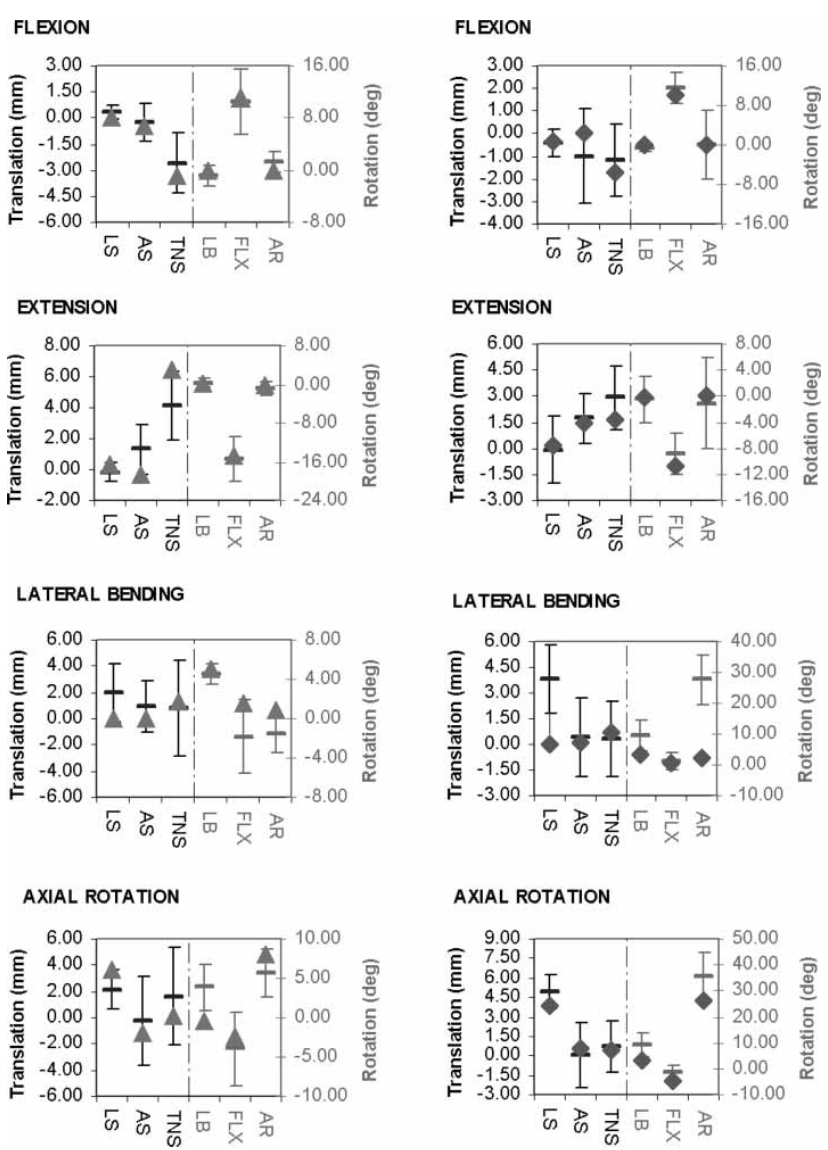

Fig. 16 Main and coupled displacements of model motion segments $\mathrm{C} 0-\mathrm{C} 1$ (left side $\boldsymbol{\Delta}$ ) and C1-C2 (right side $\diamond$ ) in response to applied rotational loads of $1.5 \mathrm{Nm}$ shown against the experimental results (average \pm SD) of Panjabi and co-workers

with the experimental data for most directions. In axial rotation the segment exhibits little to no coupled lateral bending in contrast to the reported average, this is thought to be due to the representation of the atlanto-occipital joints and their orientation. The main displacements of the $\mathrm{C} 1-\mathrm{C} 2$ segment are in reasonable to good agreement for flexion and extension loading compared with experimental data. The segment appears to be too stiff in axial rotation and lateral bending and again the coupling between lateral bending and axial rotation and visa versa is weak. Also no coupled lateral shear is seen in response to lateral bending.

\subsection{Motion segment response to large loads}

Figures 17 and 18 show the response to large loads of the segments of the lower cervical spine (C3-C4 and C5-C6). Figure 17 shows the segment response to rotational loading along with the range of motion of the segments as reported by White and Panjabi [21]. 

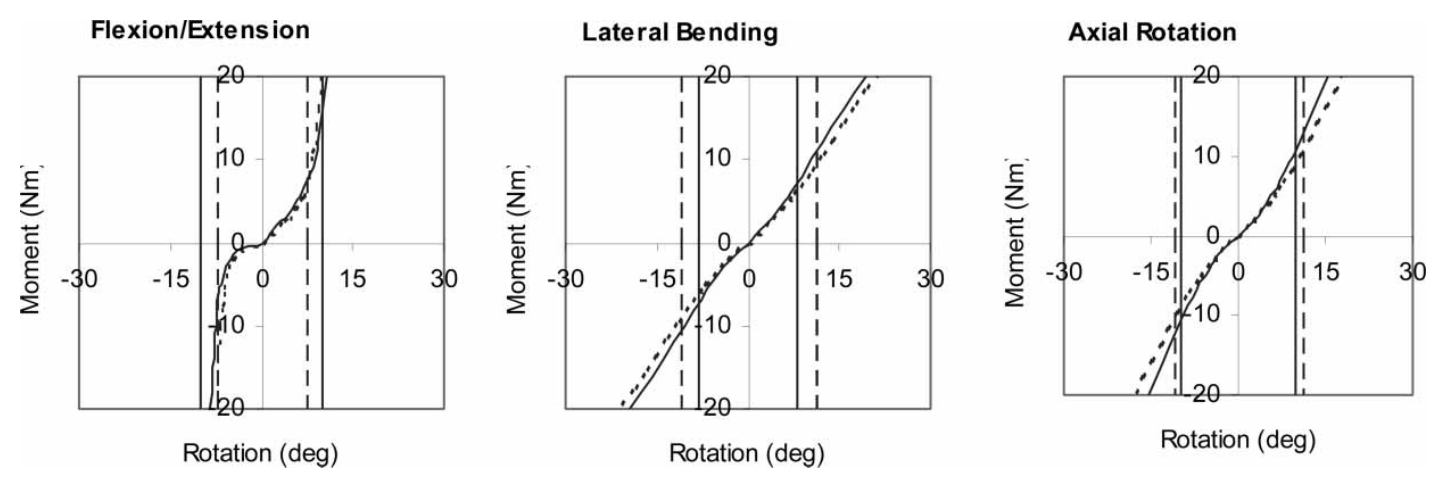

Fig. 17 Response of model motion segments C3-C4 (dashed line) and C5-C6 (solid line) to applied rotational loads of $20 \mathrm{Nm}$. The vertical lines shows the ROM for the corresponding motion segment as reported by White and Panjabi [21]
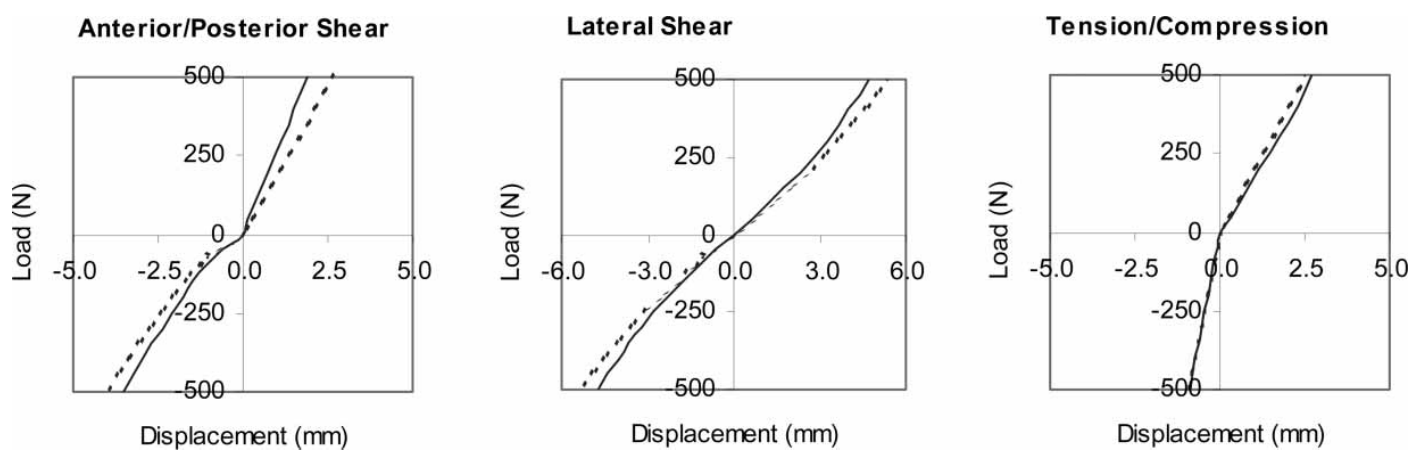

Fig. 18 Response of model motion segments C3-C4 (dashed line) and C5-C6 (solid line) to applied translational loads of $500 \mathrm{~N}$

Figure 18 shows the translational response of the segments, no experimental data on the translational range of motion segments of the lower cervical spine is available for comparison.

It can be seen that, for larger displacements, stiffness of the segments increases due to the resistive forces of the non-linear ligaments and of the discs as they become more and more strained. In flexion and extension a clear neutral zone can be seen where only a small load is needed to significantly displace the segment. For other loading directions the neutral zones are not so pronounced due to the linear stiffness of the discs resulting in larger initial stiffness of the segments.

C5-C6 is stiffer than C3-C4 in all directions except for flexion and extension where $\mathrm{C} 5-\mathrm{C} 6$ is slightly more flexible than C3-C4, which is in agreement with the results of White and Panjabi. The combined flexion and extension of C3-C4 and C5-C6 are $17^{\circ}$ and $19^{\circ}$, respectively, compared to the reported ROM of $15^{\circ}$ and $20^{\circ}$. In lateral bending the segments responses are larger than the reported ROM by around 50 and 60 per cent for C3-C4 and C5-C6, respectively. Again in axial rotation the displacements exceed ROM by around 35 and 40 per cent for C5-C6 and C3-C4, respectively.
C5-C6 is slightly stiffer than C3-C4 in all shearing directions; the linearity of the discs clearly dominates the response in anterior shear, tension, and compression where no neutral zones are observed.

Figures 19 and 20 show the response to large loads of the segments of the upper cervical spine $(\mathrm{C} 0-\mathrm{Cl}$ and $\mathrm{C} 1-\mathrm{C} 2$ ). Figure 19 shows the segment response to rotational loading along with the range of motion of the segments as reported by White and Panjabi [21]. Figure 20 shows the translational response of the segments; again no experimental data on the translational range of motion segments of the upper cervical spine is available for comparison.

There is no disc present between $\mathrm{C} 0-\mathrm{C} 1$ or $\mathrm{C} 1-\mathrm{C} 2$ so all resistance to load comes from the ligaments and facet joints. Clear neutral zones in which little load is needed to deform the structure are present for all directions of rotational loading due to the non-linear response of the ligaments.

In posterior shear the motion of $\mathrm{C} 1$ with respect to $\mathrm{C} 2$ is limited by the contact between the facet on the anterior ring of $\mathrm{Cl}$ and the dens process of $\mathrm{C} 2$ while the concave-convex interaction between the atlanto-occipital joints limits both anterior and posterior shear between the occiput and C1. Anterior shear of the C1-C2 segment is limited only by 

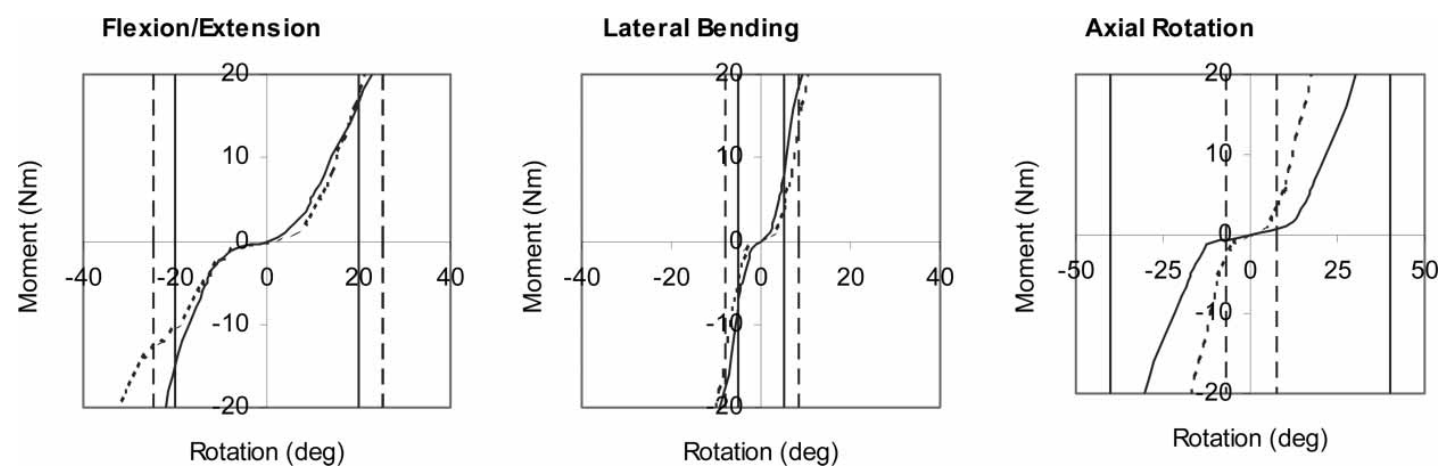

Fig. 19 Response of model motion segments $\mathrm{C} 0-\mathrm{C} 1$ (dashed line) and $\mathrm{C} 1-\mathrm{C} 2$ (solid line) to applied rotational loads of $20 \mathrm{Nm}$. The vertical dotted lines shows the ROM for the corresponding motion segment as reported by White and Panjabi [21]
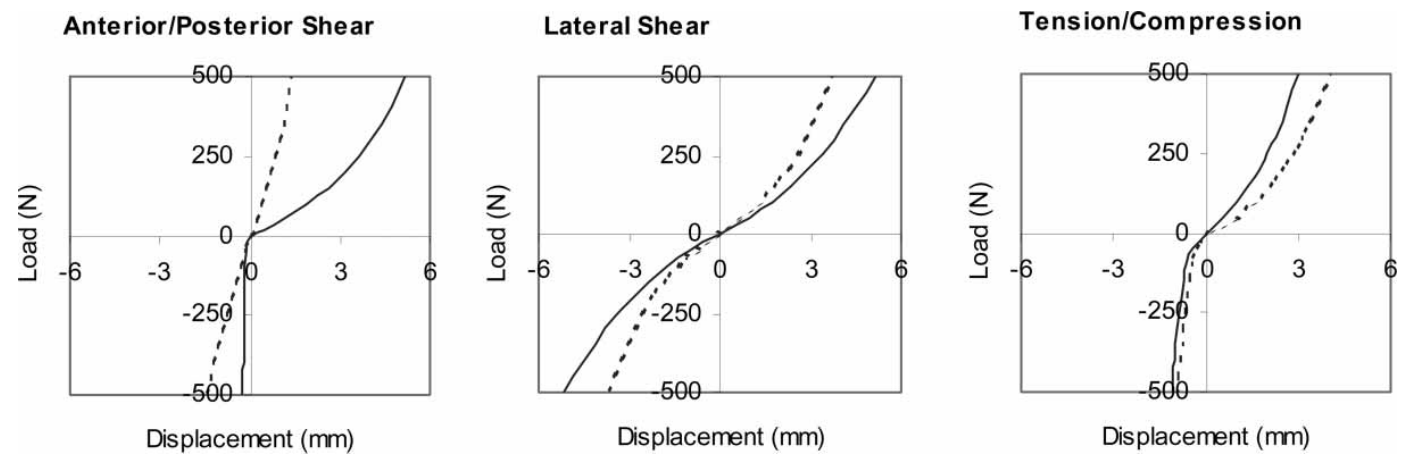

Fig. 20 Response of model motion segments $\mathrm{C} 0-\mathrm{C} 1$ (dashed line) and $\mathrm{C} 1-\mathrm{C} 2$ (solid line) to applied translational loads of $500 \mathrm{~N}$

the ligaments as can be seen by the progressive increase in load with displacement. Both segments have similar response to lateral bending, flexion, and compression. C1-C2 shows nearly 50 per cent greater flexibility in axial rotation than $\mathrm{C} 0-\mathrm{C} 1$, which is in agreement with reported ROM experiments however, C1-C2 is still too stiff and $\mathrm{C} 0-\mathrm{C} 1$ too flexible compared with the reported ROM of White and Panjabi [21].

\subsection{Response of the ligamentous cervical spine model}

Figure 21 shows the simulation results for flexion and extension loading of the entire ligamentous cervical spine model. The graphs show the moment rotation curves for each level of the spine up to a maximum of $\pm 10 \mathrm{Nm}$. Also shown on each graph are the moment rotation functions for each cervical level as defined by Camacho et al. [25] up to $\pm 2 \mathrm{Nm}$ and the average \pm SD rotation at $1.8 \mathrm{Nm}$ as reported by Moroney et al. [23]. For the upper cervical spine segment, $\mathrm{C} 0-\mathrm{C} 2$, the mean $( \pm \mathrm{SD})$ rotation at $1.5 \mathrm{Nm}$ as reported by Panjabi et al. [10] is shown along with the load-displacement curve of Camacho et al.
The results of Camacho et al. are in agreement with those reported by Moroney et al. for the lower cervical spine expect for C2-C3 in extension where Camacho et al. predicts a slightly more flexible response. At every level the model is in good agreement with the results of Camacho et al. in extension but appear to be too stiff in flexion, this is thought to be due to the greater contribution of the ligaments in flexion as five out of the six ligaments (left and right CL, PLL, FL, and ISL) at each level are tensioned while just three (ALL and left and right CL) are loaded in extension. The model is in reasonable agreement with the results of Moroney et al. although appearing to be too stiff in flexion at C6-C7 and C7-T1 and too flexible in extension at C2-C3. For the upper cervical spine segment $\mathrm{C} 0-\mathrm{C} 2$ the models response is in good agreement with the experimental results.

\subsection{Coupling characteristics of the model}

From the results of the small load simulations (Fig. 1) it can be seen that the lower cervical spine segments exhibit the characteristic coupling of anterior shear with flexion and posterior shear with extension. In flexion, however, the amount of coupled 

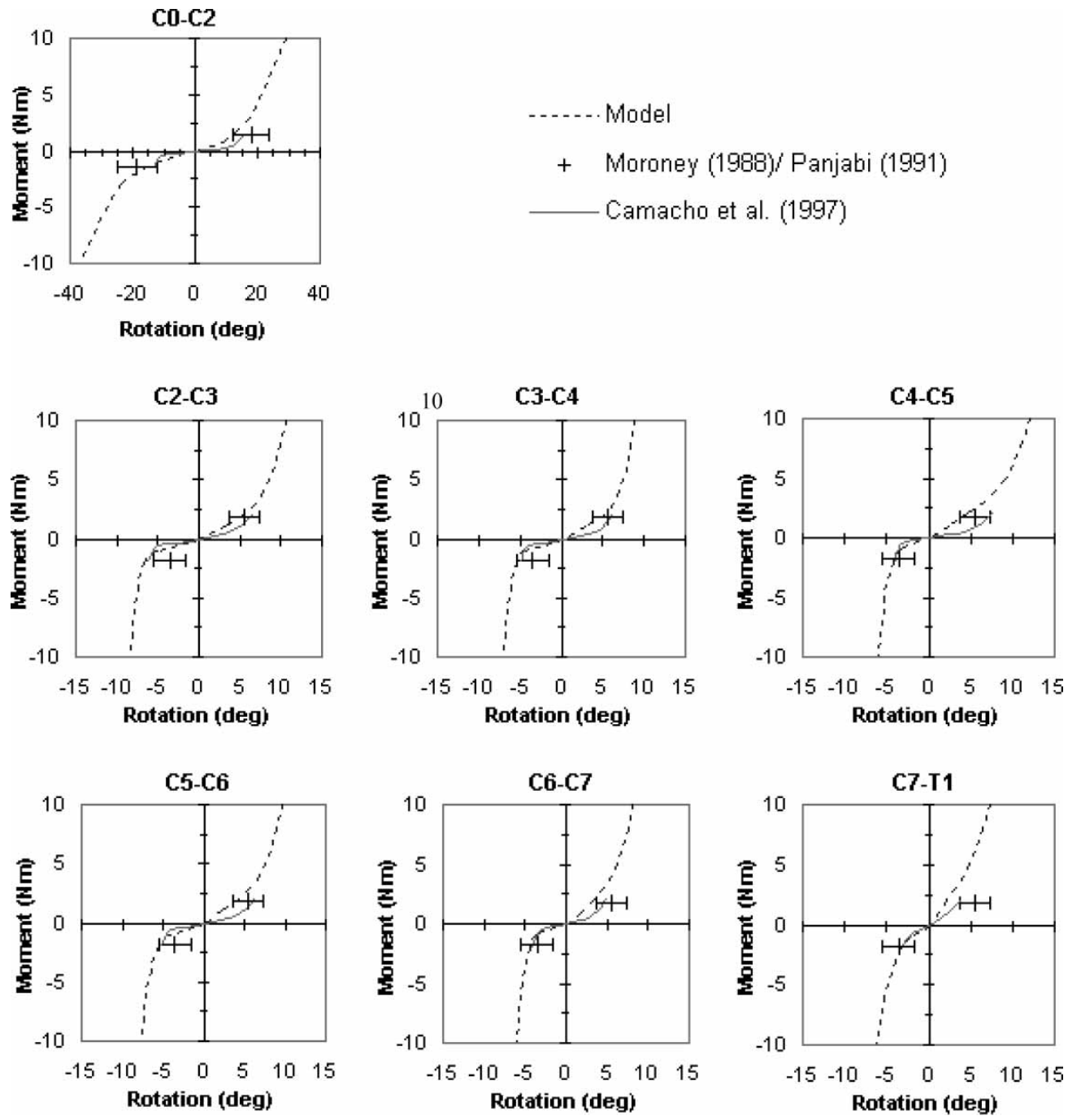

Fig. 21 Flexion (+Rotation) and extension (-Rotation) response of each level of the ligamentous cervical spine model compared against the torque-rotation functions of Camacho et al. [25] and the static small load displacements reported by Moroney et al. [23] (C2-C7) and Panjabi et al. [10] (C0-C2)

anterior shear is small compared to the results of Moroney et al.

It can be seen from the small load simulations that axial rotation is coupled with lateral bending and also that lateral bending is coupled with axial rotation for both lower cervical spine motion segments tested. For segment C3-C4 there are 1.76 deg of coupled right axial rotation with $3.04 \mathrm{deg}$ of right lateral bending, a ratio of 0.58 . This is in agreement with White and Panjabi [21] who state a ratio of 0.67 . At C5-C6 the ratio reduces to 0.48 , which is in agreement with the theory that there is a gradual decrease in the amount of axial rotation that is associated with lateral bending the further down the cervical spine you go.

Similarly for coupled lateral bending with axial rotation the ratios are 0.64 and 0.78 for $\mathrm{C} 3-\mathrm{C} 4$ and $\mathrm{C} 5-\mathrm{C} 6$, respectively. Results of Moroney et al. give a lower but still comparable ratio of 0.51 .

Mimura et al. [59] presented the ROM for the lower cervical spine in axial rotation along with the range of coupled lateral bending at each vertebral level determined by Biplanar radiography. The load required to produce the ROM was not reported making it difficult to reproduce the experiments, however, it is still useful to compare the level of coupled motion when a similar degree of axial rotation is reached in the head-neck model. It was found that an applied load of $5 \mathrm{Nm}$ at C0 produced a comparable amount of axial rotation at each level of the lower cervical spine. Figure 22 shows the simulated response at each level compared against the results of Mimura et al. (average \pm SD) for axial rotation and coupled lateral bending. The models response is in good agreement with 

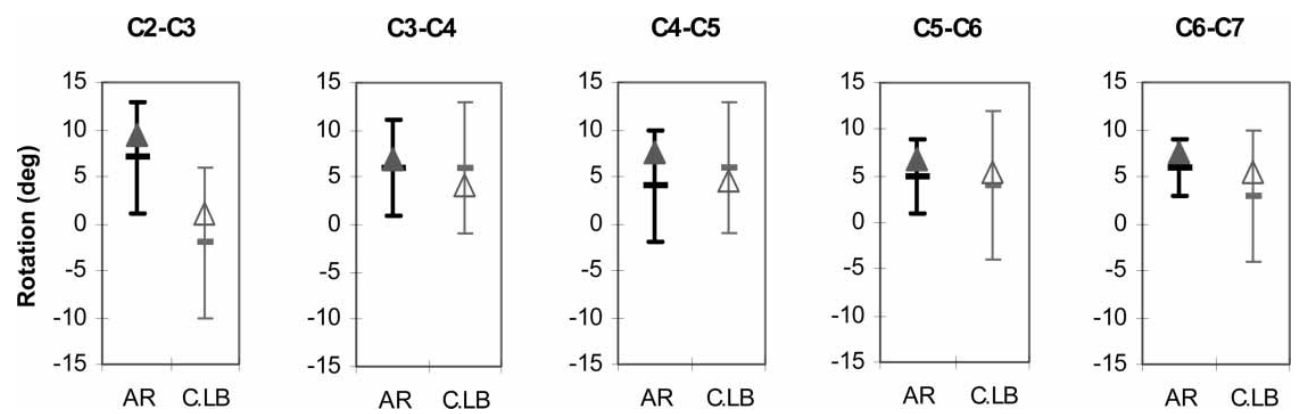

Fig. 22 Normal range of motion of the lower cervical spine in axial rotation (AR) and range of coupled lateral bending (C.LB) shown against the results of Mimura et al. (average \pm SD). Rotational displacement is shown on the vertical axis. The models response at each level is shown by $(\boldsymbol{\Lambda})$ for AR and by $\Delta$ for C.LB

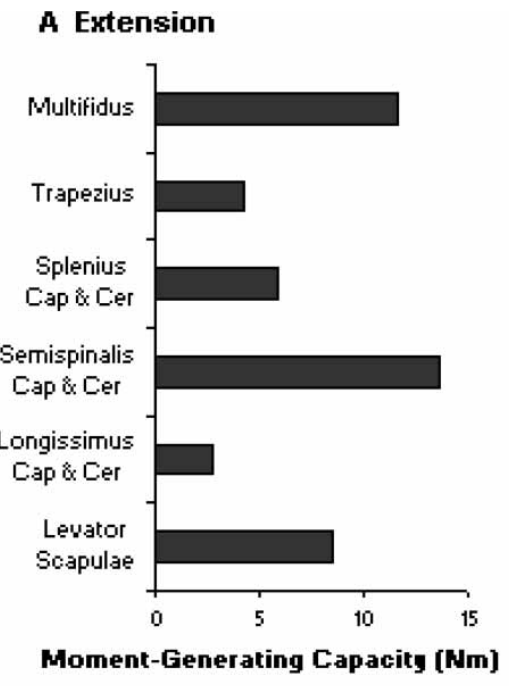

C Axial Rotation

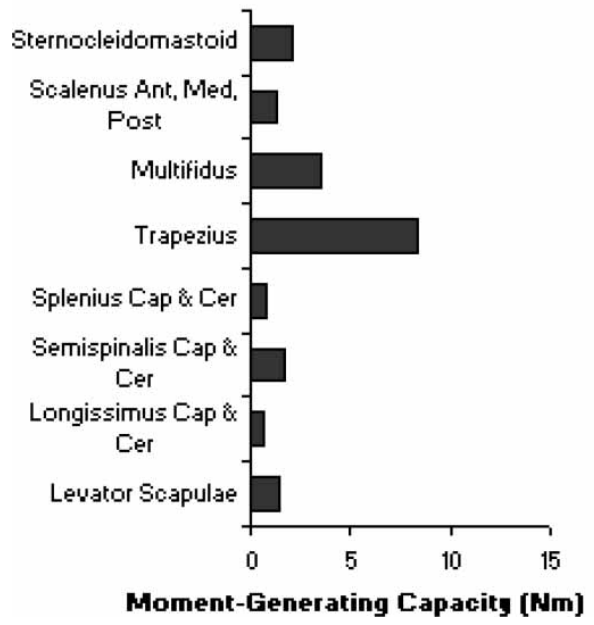

B Flexion

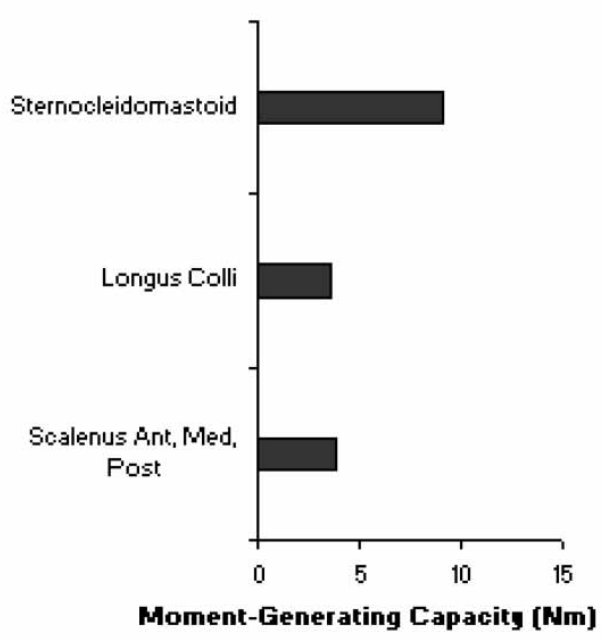

D Lateral Bending

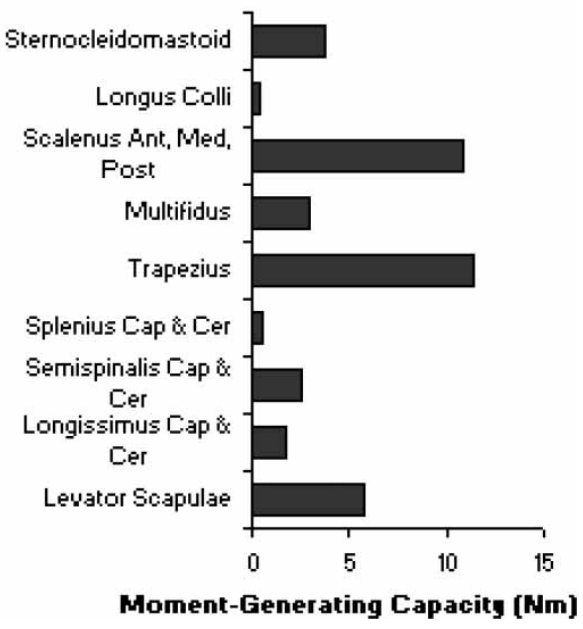

Fig. 23 Moment-generating capacity of the muscle groups of the head-neck model in the initial position. Extension/flexion: total contribution of each muscle group on both sides of the neck. Axial rotation/lateral bending: total contribution of each muscle groups on one side only 
the experimental data demonstrating that a similar level of coupled lateral bending is reached at each level of the lower cervical spine model.

\subsection{Moment-generating capacity of the neck muscle elements}

With all muscles maximally activated, the model estimates a total extension moment of $47 \mathrm{Nm}$ with the Semispinalis capitis and cervicis (29 per cent), Multifidus (25 per cent) and Levator scapulae (18 per cent), having the most significant contribution. The remaining 28 per cent of the total extension moment is generated by the Longissimus, Splenius, and Trapezius muscles (Fig. 23). The Sternocleidomastoid produces over half the flexion moment about T1 (55 per cent) with the other half shared fairly evenly between the three Scalenus muscles (24 per cent) and the Longus colli (22 per cent) (Fig. 23). The total axial rotation moment (Fig. 23) is predicted to be $19 \mathrm{Nm}$ with the Trapezius muscle having the most significant contribution (41 per cent). Finally for lateral bending the total moment-generating capacity is $39 \mathrm{Nm}$ with the Trapezius (29 per cent) and Scalenus (27 per cent) muscles providing over half the moment with the Levator scapulae, Sternocleidomastoid, and Multifidus also providing significant contributions (Fig. 23). Table 6 compares the moments generated about T1 with those measured in a number of studies. It is thought that these values are in close enough agreement with the experimental values presented. It should be noted that the value of specific tension used in the model simulations was $50 \mathrm{~N} / \mathrm{cm}^{2}$, thought to represent an average male with reasonably developed musculature. Clearly the choice of specific tension value will affect the total moment-generating capacity predicted by the model but will not affect the relative contributions of the muscles.

\section{DISCUSSION}

The improvements of the new model in comparison to previous multi-body and finite elements models of the head and neck are in the detailed representation of the cervical vertebrae, the more accurate properties of the soft tissues, and in the complexity of the muscle elements. More detail in the geometry of the vertebrae has been included in this model than seen in other multi-body models allowing for more accurate location of muscle and ligament attachment sites. Also the geometry is based on mean data from experimental measurements of human vertebrae as opposed to direct measurements from a single spine specimen, hence this method will give a more general representation of an average adult human neck.
The head-neck model has been evaluated to check the accuracy of the individual components, motion segments and the model as a whole in response to different loading conditions. The evaluation and validation of the cervical spine model has shown that the model is in good agreement with experimental findings from actual human cervical spine specimens. The model segments have been tested to show main and coupled motions to be accurate and realistic. It has been shown that the model can predict the loads and deformations of the individual soft-tissue elements making the model suitable for injury analysis. The validation of the muscle elements shows the morphometric values, origins, and insertions selected to be reasonable.

In conclusion, the multi-body model developed is capable of simulating both the global and local kinematics of the head with respect to the torso and of the individual vertebrae and soft-tissue elements.

\section{ACKNOWLEDGEMENT}

The authors gratefully acknowledge the $\mathrm{PhD}$ studentship received from the EPSRC (Engineering and Physical Sciences Council) of the United Kingdom for this research.

\section{REFERENCES}

1 Jakobsson, L., Norin, H., Jernström, C., Svensson, S.-E., Johnsen, P., Isaksson-Hellman, I., and Svensson, M. Y. Analysis of different head and neck responses in rearend car collisions using a new humanlike mathematical model. In Proceedings of the 1994 International IRCOBI Conference, Lyon, France, 1994, pp. 109-125.

2 De Jager, M. K. J. Mathematical head-neck models for acceleration impacts. $\mathrm{PhD}$ Thesis, Eindhoven University of Technology, Eindhoven, The Netherlands, 1996.

3 Van den Kroonenberg, A., Thunnissen, J., and Wismans, J. A human model for low-severity rear-impacts. In Proceedings of the 1997 International IRCOBI Conference, Hanover, Germany, 1997, pp. 117-132.

4 Yamazaki, K., Ono, K., and Kaneoka, K. A simulation analysis of human cervical spine motion during low Speed rear-end impacts. Society of Automotive Engineers, Warrendale, PA, SAE paper 2000-01-0154, 2000.

5 Van Der Horst, M. J. Human head neck response in frontal, lateral and rear end impact loading: modelling and validation. $\mathrm{PhD}$ Thesis, Eindhoven University of Technology, Eindhoven, The Netherlands, 2002.

6 Stemper, B. D., Yoganandan, N., and Pintar, F. A. Validation of a head-neck computer model for whiplash simulation. Med. Biol. Eng. Comput., 2004, 42(3), 333-338.

7 Nissan, M. and Gilad, I. The cervical and lumbar vertebrae-an anthropometric model. Eng. Med., 1984, 13(3), 111-114. 
8 Panjabi, M. M., Duranceau, J., Goel, V., Oxland, T., and Takata, K. Cervical human vertebrae. Quantitative three-dimensional anatomy of the middle and lower regions. Spine, 1992, 16(8), 861-869.

9 Panjabi, M. M., Oxland, T., Takata, K., Goel, V., Duranceau, J., and Krag, M. Articular facets of the human spine. Spine, 1993, 18(10), 1298-1310.

10 Panjabi, M. M., Dvorak, J., Crisco, J. J. III, Oda, T., Hilibrand, A., and Grob, D. Flexion, extension and lateral bending of the upper cervical spine in response to alar ligament transections. J. Spinal Disord., 1991, 4(2), 157-167.

11 Xu, R., Nadaud, B. A., Ebraheim, N. A., and Yeasting, R. A. Morphology of the second cervical vertebra and the posterior projection of the C2 pedicle axis. Spine, 1995, 20(3), 259-263.

12 Schaffler, M. B., Alson, M. D., Heller, J. G., and Garfin, S. R. Morphology of the dens. Spine, 1992, 17(7), 738-742.

13 Doherty, B. J. and Heggeness, M. H. The quantitative anatomy of the atlas. Spine, 1994, 19(22), 2497-2500.

14 Doherty, B. J. and Heggeness, M. H. Quantitative anatomy of the second cervical vertebrae. Spine, 1995, 20(5), 513-517.

15 Hobbs, P. C. An anthropometric survey of 500 royal air force aircrew heads. Royal Aircraft Establishment Technical Report 73137, Procurement Executive, Ministry of Defence, Farnborough, Hants, 1972.

16 Gray, H. Grays anatomy, 36th edition (Eds P. L. Williams and R. Warwick),1980 (Churchill Livingstone, London).

17 Kapandji, I. A. The physiology of the joints, the trunk and vertebral column, 2nd edition, vol. 3, 1974 (Churchill Livingstone, Edinburgh).

18 Thunnissen, J., Wismans, J., Ewing, C. L., and Thomas, D. J. Human volunteer head-neck response in frontal flexion: a new analysis. In Proceedings of the 39th Stapp Car Crash Conference, Society of Automotive Engineers. SAE paper 952721, 1995, pp. 439-460.

19 Walker, L. B., Harris, E. H., and Pontius, U. R. Mass, volume, centre of mass and mass moment of inertia of head and head and neck of the human body. In Proceeding of the 17th Stapp Car Crash Conference, Society of Automotive Engineers, SAE paper 730985, 1973, pp. 525-537.

20 Nowitzke, A., Westaway, M., and Bogduk, N. Cervical zygapophysial joints: geometrical parameters and relationship to cervical kinematics. Clin. Biomech., 1994, 9 342-347.

21 White, A. A. III and Panjabi, M. M. Clinical biomechanics of the spine, 2nd edition, 1990 (J.B. Lippincott Company, Philadelphia, Toronto).

22 Tominaga, T., Dickman, C. A., Sonntag, V. K. H., and Coons, S. Comparative anatomy of the baboon and the human cervical spine. Spine, 1995, 20(2), 131-137.

23 Moroney, S. P., Schultz, A. B., Miller, J. A. A., and Andersson, G. B. J. Load-displacement properties of lower cervical spine motion segments. J. Biomech., 1988, 21 (9), 769-779.

24 Yoganandan, N., Kumaresan, S., and Pintar, F. A. Biomechanics of the cervical spine part 2. Cervical spine soft tissue responses and biomechanical modelling. Clin. Biomech., 2001, 16, 1-27.
25 Camacho, D. L., Nightingale, R. W., Robinette, J. J., Vanguri, S. K., Coates, D. J., and Myers, B. S. Experimental flexibility measurements for the development of a computational head-neck model validated for near-vertex Head impact. In Proceedings of the 41st Stapp Car Crash Conference, Society of Automotive Engineers, SAE paper 973345, 1997, pp. 473-486.

26 Panjabi, M. M., Oxland, T. R., and Parks, E. H. Quantitative anatomy of cervical spine ligaments. Part 1. Upper cervical spine. J. Spinal Disord., 1991c, 4(3), 270-276.

27 Yoganandan, N., Kumaresan, S., and Pintar, F. A. Geometric and mechanical properties of human cervical spine ligaments. J. Biomech. Eng., 2000, 122, 623-629.

28 Chazal, J., Tanguy, A., Bourges, M., Gaurel, G., Escande, G., Guillot, M., and Vanneuville, G. Biomechanical properties of spinal ligaments and a histological study of the supraspinal ligament in traction. J. Biomech., 1985, 18(3), 167-176.

29 Hill, A.V. First and last experiments in muscle mechanics, 1970 (Cambridge University Press, Cambridge).

30 Zajac, F. E. Muscle and tendon: properties, models, scaling and application to biomechanics and motor control. Crit. Rev. Biomed. Eng., 1989, 17, 359-411.

31 Brown, I. E. and Loeb, G. E. Measured and modelled properties of mammalian skeletal muscle: IV. Dynamics of activation and deactivation. J. Muscle Res. Cell Motil., 2000, 21, 33-47.

32 Brown, I. E., Cheng, E. J., and Loeb, G. E. Measured and modelled properties of mammalian skeletal muscle: II. The effects of stimulus frequency on force-length and force-velocity relationships. J. Muscle Res. Cell Motil., 1999, 20, 627-643.

33 Cheng, E. J., Brown, I. E., and Loeb, G. E. Virtual muscle: a computational approach to understanding the effects of muscle properties on motor control. J. Neurosci. Methods, 2000, 101, 117-130.

34 Herzog, W., Kamal, S., and Clarke, H. D. Myofilament lengths of cat skeletal muscle: theoretical considerations and functional implications. J. Biomech., 1992, 25, 945-948.

35 Rack, P. M. H. and Westbury, D. R. The effects of length and stimulus rate on tension in the isometric cat soleus muscle. J. Physiol., 1969, 204, 443-460.

36 Scott, S. H., Brown, I. E., and Loeb, G. E. Mechanics of feline soleus: I. Effect of fascicle length and velocity on force output. J. Muscle Res. Cell Motil., 1996, 17, 207-219.

37 Brown, I. E., Satoda, T., Richmond, F. J. R., and Loeb, G. E. Feline caudofermoralis muscle. Muscle fiber properties, architecture and motor innervation. Exper. Brain Res., 1998, 121, 76-91.

38 Winters, J. M. and Stark, L. Estimated mechanical properties of synergistic muscles involved in movements of a variety of human joints. J. Biomech., 1988, 21, 1027-1041.

39 Kamibayashi, L. K. and Richmond, F. J. R. Morphometry of human neck muscles. Spine, 1998, 23(12), 1314-1323.

40 Cheng, E. J., Brown, I. E., and Loeb, G. E. Virtual muscle 3.1.5: muscle model for matlab. Users manual, 2001, available from http://ami.usc.edu/Projects/ MuscluarModeling/index.asp. 
41 Snyder, R. G., Chaffin, D. B., and Foust, D. R. Bioengineering study of basic physical measurements related to susceptibility to cervical hyperextensionhyperflexion injury. Report UM-HSRI-BI-75-6, Highway Safety Research Institute, University of Michigan, Ann Arbor, Michigan, 1975.

42 Reid, S. E. and Raviv, G. Neck muscle resistance to head impact. Aviat. Space Environ. Med., 1981, 52(2), 78-84.

43 Ono, K., Kaneoka, K., Wittek, A., and Kajzer, J. Cervical injury mechanism based on the analysis of human cervical vertebral motion and head-neck-torso kinematics during low speed rear impacts. In Proceedings of the 41st Stapp Car Crash Conference, Society of Automotive Engineers, SAE paper 973340, 1997, pp. 339-356.

44 Brault, J. R., Siegmund, G. P., and Wheeler, J. B. Cervical muscle response during whiplash: evidence of a lengthening muscle contraction. Clin. Biomech., 2000, 15, 426-443.

45 The vertebral column, Anatomical Chart no. C9850PL, 1992 (Adam, Rouilly Ltd, Sittingbourne, Kent).

46 Gurumoorthy, D. and Twomey, L. T. Morphology of cervical muscles and relevance to whiplash. In Frontiers in whiplash trauma. Clinical and biomechanical (Eds N. Yoganandan and F. A. Pintar), 2000, pp. 60-71 (IOS Press, Amsterdam).

47 Warfel, J. H. The head, neck and trunk, 5th edition, 1985 (Lea and Febiger, Philadelphia).

48 Johnson, G., Bogduk, N., Nowitzke, A., and House, D. Anatomy and actions of the trapezius muscle. Clin. Biomech., 1994, 9, 44-50.

49 Vasavada, A. N., Li, S., and Delp, S. L. Influence of muscle morphometry and moment arms on the momentgenerating capacity of human neck muscles. Spine, 1998, 23(4), 412-422.

50 Van Der Horst, M. J., Thunnissen, J. G. M., Happee, R., Van Haaster, R. M. H. P., and Wismans, J. S. H. M. The influence of muscle activity on the head-neck response during impact. SAE Trans., 1997, 106(2), 4003-4023.

51 van Lopik, D. W. and Acar, M. Dynamic verification of a multi-body computational model of human head and neck for frontal, lateral, and rear impacts. Proc. IMechE, Park K: J. Multi-body Dynamics, 2007, 221(K2), 199-217 (this issue).

52 Panjabi, M. M., Dvorak, J., Duranceau, J., Yamamoto, I., Geber, M., Rausching, W., and Bueff, H. U. Threedimensional movements of the upper cervical spine. Spine, 1988, 13, 726-730.

53 Panjabi, M. M., Dvorak, J., Crisco, J. J. III, Oda, T., Wang, P., and Grob, D. Effects of alar ligament transection on upper cervical spine rotation. J. Orthop. Res., 1991b, 9, 584-593.

54 Oda, T., Panjabi, M. M., and Crisco, J. J. III Threedimensional movements of the upper cervical spine. J. Spinal Disord., 1991, 4, 411-419.
55 Oda, T., Panjabi, M. M., Crisco, J. J. III, Bueff, H. U., Grob, D., and Dvorak, J. Role of tectorial membrane in the stability of the upper cervical spine. Clin. Biomech., 1992, 7, 201-207.

56 Milne, N. The role of zygapophysial joint orientation and uncinate processes in controlling motion in the cervical spine. J. Anat., 1991, 178, 189-201.

57 Bogduk, N. and Mercer, S. Biomechanics of the cervical spine. 1: normal kinematics. Clin. Biomech., 2000, 15, 633-648.

58 Vasavada, A. N., Li, S., and Delp, S. L. Three-dimensional isometric strength of neck muscles in humans. Spine, 2001, 26(17), 1904-1909.

59 Mimura, M., Moriya, H., Watanabe, T., Takahashi, K., Yagmagata, M., and Tamaki, T. I. Three-dimensional motion analysis of the cervical spine with special reference to the axial rotation. Spine, 1989, 14, 1135-1139.

60 Winters, J. M. and Woo, S. L.-Y. Multiple muscle systems: biomechanics and movement organization, 1990 (Springer-Verlag, New York).

61 Richmond, F. J. R., Singh, K., and Corneil, B. D. Neck muscles in the rhesus monkey. I. Muscle morphometry and histochemistry. J. Neurosci., 2001, 86, 1717-1728.

62 Boyd-Clarke, L. C., Briggs, C. A., and Galea, M. P. Comparative histochemical composition of muscle fibres in a pre- and a postvertebral muscle of the cervical spine. J. Anat., 2001, 199, 709-716.

63 Harms-Ringdahl, K. and Schuldt, K. Maximum neck extension strength and relative neck muscular load in different cervical spine positions. Clin. Biomech., 1988, 4, 17-24.

64 Jordan, A., Mehlsen, J., and Bulow, P. M. Maximum isometric strength of the cervical musculature in 100 healthy volunteers. Spine, 1999, 24, 1343-1348.

65 Mayoux-Benhamou, M. A. and Revel, M. Influence of head position on dorsal neck muscle efficiency. Electromyogr. Clin. Neurophysiol., 1993, 33, 161-166.

66 Queisser, F., Bluthner, R., and Seidel, H. Control of positioning the cervical spine and its application to measuring extensor strength. Clin. Biomech., 1994, 9, 157-161.

\section{BIBLIOGRAPHY}

van Lopik, D. W. A computational model of the human head and cervical spine for dynamic impact simulation. $\mathrm{PhD}$ Thesis, Loughborough University, Loughborough, UK, 2004. 
